OPEN ACCESS

Edited by:

Cosima T. Baldari,

University of Siena, Italy

Reviewed by:

Lawrence Kane,

University of Pittsburgh, United States

Klaus Okkenhaug,

University of Cambridge,

United Kingdom

${ }^{*}$ Correspondence:

Doreen A. Cantrell

d.a.cantrell@dundee.ac.uk

${ }^{\dagger}$ Present address:

Aneela Nomura,

Laboratory for Transcriptional

Regulation, RIKEN Center for

Integrative Medical Sciences,

Yokohama, Japan

Marcos P. Damasio,

Massachusetts General Hospital,

Boston, MA, United States

Specialty section:

This article was submitted to

$T$ Cell Biology,

a section of the journal

Frontiers in Immunology

Received: 07 April 2021 Accepted: 27 May 2021

Published: 18 June 2021

Citation:

Spinelli L, Marchingo JM, Nomura A, Damasio MP and Cantrell DA (2021) Phosphoinositide 3-Kinase p110 Delta

Differentially Restrains and Directs

Naïve Versus Effector CD8 ${ }^{+} \mathrm{T}$ Cell

Transcriptional Programs.

Front. Immunol. 12:691997.

doi: 10.3389/fimmu.2021.691997

\section{Phosphoinositide 3-Kinase} p110 Delta Differentially Restrains and Directs Naïve Versus Effector $\mathrm{CD8}^{+} \mathrm{T}$ Cell Transcriptional Programs

\author{
Laura Spinelli, Julia M. Marchingo, Aneela Nomura ${ }^{\dagger}$, Marcos P. Damasio $^{\dagger}$ \\ and Doreen A. Cantrell* \\ Division of Cell Signalling and Immunology, School of Life Sciences, University of Dundee, Dundee, United Kingdom
}

Phosphoinositide 3-kinase p110 delta (PI3K p1108) is pivotal for CD8 ${ }^{+} \mathrm{T}$ cell immune responses. The current study explores PI3K p110 induction and repression of antigen receptor and cytokine regulated programs to inform how PI3K p110 directs CD8 ${ }^{+} \mathrm{T}$ cell fate. The studies force a revision of the concept that PI3K p110 $\delta$ controls metabolic pathways in T cells and reveal major differences in PI3K p110 regulated transcriptional programs between naiive and effector cytotoxic $T$ cells (CTL). These differences include differential control of the expression of cytolytic effector molecules and costimulatory receptors. Key insights from the work include that PI3K p110 signalling pathways repress expression of the critical inhibitory receptors CTLA4 and SLAMF6 in CTL. Moreover, in both naïve and effector $T$ cells the dominant role for PI3K p110 is to restrain the production of the chemokines that orchestrate communication between adaptive and innate immune cells. The study provides a comprehensive resource for understanding how PI3K p110 1 uses multiple processes mediated by Protein Kinase B/ AKT, FOXO1 dependent and independent mechanisms and mitogen-activated protein kinases (MAPK) to direct $C D 8^{+} \mathrm{T}$ cell fate.

Keywords: PI3K, p1108, CD8+ T cells, TCR signalling, transcriptomics, cytokines, chemokines

\section{INTRODUCTION}

$\mathrm{CD}^{+}$cytotoxic $\mathrm{T}$ cells are critical cells for mammalian adaptive immune responses that clear pathogen infected cells. The proliferation and differentiation of $\mathrm{CD} 8^{+} \mathrm{T}$ cells into cytolytic effector cells (CTL) is directed by an integrated network of signals driven by the $\mathrm{T}$ cell antigen receptor (TCR) and modulated by cytokines and cytokine receptors and costimulatory and inhibitory receptors $(1,2)$. One rapid consequence of TCR engagement in $\mathrm{CD}^{+} \mathrm{T}$ cells is the production of phosphatidylinositol 3,4,5-trisphosphate $\left(\operatorname{PtdIns}(3,4,5) P_{3}\right)$, the product of phosphoinositide 3kinase (PI3K). CD ${ }^{+}$T cells thus rapidly accumulate PtdIns $(3,4,5) P_{3}$ following TCR engagement (3-5) and sustain high levels of PtdIns $(3,4,5) P_{3}$ as they differentiate to effector CTL $(6,7)$. Cellular levels of PtdIns $(3,4,5) P_{3}$ in T cells are controlled by a PI $3 \mathrm{~K}$ complex that contains the p110 $\delta$ catalytic 


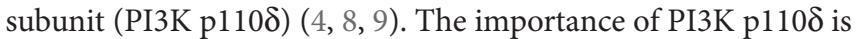
emphasised by the discovery that both loss and gain of function mutations of PI3K p $110 \delta$ cause primary immunodeficiency and autoimmunity in humans and mice (10-13). Effective PI3K p110 $\delta$ inhibitors, used clinically to treat immune dysfunction and cancer, are available (14-17).

The importance of PI3K p $110 \delta$ for T cells makes it important to understand the molecular details of how it controls $\mathrm{T}$ cell function. In this context, PtdIns $(3,4,5) P_{3}$ controls the activity of the serine/threonine kinase $\mathrm{PKB} / \mathrm{AKT}$ which phosphorylates the transcription factor FOXO1 causing its exclusion from the nucleus and terminating FOXO1 controlled transcription. In naïv $\mathrm{T}$ cells, FOXO1 controls expression of transcription factors and cytokine receptors that maintain $\mathrm{T}$ cell quiescence (18). FOXO1 also controls expression of the adhesion molecules and chemokine receptors that instruct $\mathrm{T}$ cell trafficking to secondary lymphoid tissue (19-21). In pathogen activated and effector CTL, PI3K p $110 \delta$ signalling keeps FOXO1 cytosolic and inactive (22) to maintain $\mathrm{CD}^{+} \mathrm{T}$ cell effector function (23). The loss of $\mathrm{PKB} / \mathrm{AKT}$ activity causes nuclear relocation of FOXO1 resulting in the induction of the transcriptional program required for memory T cells $(18,23)$. FOXO1 is thus essential for memory $\mathrm{CD}^{+} \mathrm{T}$ cell formation and maintenance (24-27) and may control $\mathrm{T}$ cell exhaustion during chronic viral infections by to controlling the expression of the inhibitory receptor PD-1 and regulating $\mathrm{T}$ cell survival (28).

FOXO1 studies have given important insights about how PI3K p110 $\delta$ controls $\mathrm{CD} 8^{+} \mathrm{T}$ cells but it is pertinent that PI3K p110 signalling pathways go beyond the control of FOXO1. There are thus multiple substrates for PKB/AKT and PI3K p $110 \delta$ also modulates the activity of mitogen-activated protein (MAP) kinases $(29,30)$. Furthermore, there has never been an unbiased analysis or direct comparison of how PI $3 \mathrm{~K}$ p $110 \delta$ shapes transcriptomes and proteomes in naïve versus effector $\mathrm{CD}^{+} \mathrm{T}$ cells. In this respect, signal transduction outcomes can be shaped by the epigenetic and metabolic remodelling that accompanies $\mathrm{T}$ cell differentiation. Hence in naïve T cells the role of the TCR is to initiate expression of biosynthetic and transcriptional programs that drive $\mathrm{T}$ cell clonal expansion and differentiation. In effector $\mathrm{CD} 8^{+} \mathrm{T}$ cells these programs are controlled by proinflammatory cytokines and the role of the TCR is to trigger execution of effector function (e.g. the production of cytokines and degranulation of cytolytic effector molecules).

Accordingly, the current objective was to use RNA sequencing, proteomic and secretome analysis to define the contribution of PI3K p110 $\delta$ to antigen receptor regulated programs in naïve and effector $\mathrm{CD} 8^{+} \mathrm{T}$ cells. For mechanistic insights, we examined PI $3 \mathrm{~K}$ p $110 \delta$ controlled responses in wild type (WT) and FOXO1 null effector CTL to understand how much of PI3K signalling is directed by FOXO1. We also assessed the importance of $\mathrm{PKB} / \mathrm{AKT}$ and the MAP kinases as mediators of PI3K p $110 \delta$ responses. This work provides a comprehensive understanding of the targets for PI $3 \mathrm{~K}$ p $110 \delta$ signals in antigen receptor activated naïve and effector $\mathrm{CD} 8^{+} \mathrm{T}$ cells and creates the information framework necessary to predict the implications of the therapeutic manipulation of PI3K p $110 \delta$ for $\mathrm{CD}^{+} \mathrm{T}$ cells.

\section{MATERIALS AND METHODS}

\section{Mice}

For naïve and $24 \mathrm{~h}$ activated $\mathrm{CD} 8^{+} \mathrm{T}$ cells \pm PI3K p110 inhibitor, unstimulated and $4 \mathrm{~h}$ TCR activated CTL \pm PI3K p110 $\delta$ inhibitor transcriptomes, P14 transgenic mice (31) were used (female mice, 9-13 weeks old).

FOXO1-GFP ${ }^{\mathrm{fl} / \mathrm{fl}}$ mice were generated at Taconic. To allow conditional deletion of FOXO1, exon 2, which includes the EGFP sequence, was flanked by LoxP sites (32). Then to allow the deletion of FOXO1-GFP in effector T cells, FOXO1-GFP ${ }^{\mathrm{f} / \mathrm{fl}}$ mice were crossed to mice expressing the Cre recombinase under the control of the granzyme B promoter sequence [Supplementary Figure 5B and $(33,34)]$ generating FOXO1-GFP ${ }^{\mathrm{fl} / \mathrm{fl}} \mathrm{GzmB}$ cre mice.

Female FOXO1-GFP ${ }^{\mathrm{A} / \mathrm{fl}}$ GzmB cre+ mice and control GzmB cre+ mice aged between 11 and 27 weeks were used for RNA sequencing of CTL cultured for $24 \mathrm{~h}$ in the presence or absence of inhibitor. In some experiments FOXO1-GFP ${ }^{\mathrm{fl} / \mathrm{fl}}$ GzmB cre- mice were used as controls. Experimental mice were age and sex matched. Mice were bred and maintained in the Biological Resource Unit at the University of Dundee using procedures that were approved by the University Ethical Review Committee and under the authorisation of the UK Home Office Animals (Scientific Procedures) Act 1986.

\section{Cell Cultures}

All cells were activated and cultured in complete RPMI 1640 media containing glutamine (Thermo Fisher Scientific/Gibco), supplemented with 10\% FBS (Gibco), penicillin/streptomycin (Gibco) and $50 \mu \mathrm{M}$ ß-mercaptoethanol (Sigma). All cells were cultured at $37^{\circ} \mathrm{C}$ with $5 \% \mathrm{CO}_{2}$.

-For ex vivo naïve $\mathrm{CD}^{+}{ }^{+} \mathrm{T}$ cells, $24 \mathrm{~h}$ TCR activated and $24 \mathrm{~h}$ TCR activated in the presence of the PI $3 \mathrm{~K}$ p $110 \delta$ inhibitor IC87114 (10 $\mu \mathrm{M}$ synthesized in-house), three mice were used per biological replicate. Cells from the three mice were pooled and then equally divided into the three conditions. Three biological replicates were generated per condition. Single cell suspensions were generated by mashing lymph nodes in RPMI media and filtered through a $70 \mu \mathrm{m}$ cell strainer. For $24 \mathrm{~h}$ TCR activated $\mathrm{CD} 8^{+} \mathrm{T}$ cells, they were suspended in complete RPMI media with $100 \mathrm{ng} / \mathrm{ml}$ antigenic peptide [glycoprotein amino acids 33-41 (gp33-41)], 20 ng/ml interleukin-2 (IL-2; Proleukin, Novartis) and $2 \mathrm{ng} / \mathrm{ml}$ interleukin-12 (IL-12; PeproTech). Where indicated, cells were treated with $10 \mu \mathrm{M}$ IC87114 inhibitor. DMSO was used as vehicle control. After $24 \mathrm{~h}$, cells were harvested by centrifugation and prepared for cell sorting to isolate pure $\mathrm{CD} 8^{+} \mathrm{T}$ cell populations.

-To generate CTL from P14 transgenic mice, lymph nodes or spleens from three mice were used to generate three biological replicates. Lymph nodes were homogenised as described above. Spleens were mashed in red blood cell lysis buffer $(150 \mathrm{mM}$ $\mathrm{NH}_{4} \mathrm{Cl}, 10 \mathrm{mM} \mathrm{KHCO}, 110 \mu \mathrm{M} \mathrm{Na} \mathrm{NDDTA}_{2} \mathrm{pH}$ 7.8), filtered through a $70 \mu \mathrm{m}$ cell strainer and then suspended in complete RPMI media supplemented with $100 \mathrm{ng} / \mathrm{ml}$ gp33-41 peptide, $20 \mathrm{ng} / \mathrm{ml} \mathrm{IL}-2$ and $2 \mathrm{ng} / \mathrm{ml} \mathrm{IL-12}$ in $10 \mathrm{ml}$ complete RPMI. 
Cells were activated for $48 \mathrm{~h}$, then washed out and cultured for a further five days in complete RPMI media supplemented with 20 $\mathrm{ng} / \mathrm{ml} \mathrm{IL-2}$. Cells were maintained at a cell density of $0.3 \times 10^{6}$ live cells $/ \mathrm{ml}$.

For transcriptomic and proteomic studies and western blotting of TCR stimulated CTL: on day seven CTL were plated at a cell density of $1 \times 10^{6}$ live cells $/ \mathrm{ml}$ in complete RPMI media supplemented with $20 \mathrm{ng} / \mathrm{ml} \mathrm{IL-2}$ and left to rest at $37^{\circ} \mathrm{C}$ with $5 \% \mathrm{CO}_{2}$ for $1 \mathrm{~h}$. CTL were then stimulated by adding $100 \mathrm{ng} / \mathrm{ml} \mathrm{gp33-41} \mathrm{peptide} \mathrm{directly} \mathrm{to} \mathrm{the} \mathrm{supplemented} \mathrm{media}$ for $4 \mathrm{~h}$ in the presence or absence of IC87114 inhibitor $(10 \mu \mathrm{M})$, or MEK inhibitor PD184252 (2 $\mu \mathrm{M}$, Division of Signal Transduction Therapy (DSTT) Dundee). DMSO was used as vehicle control. Cells were harvested, washed twice with HBSS (Thermo Fisher Scientific/Gibco), snap frozen in liquid nitrogen and stored at $-80^{\circ} \mathrm{C}$ until further processing.

For secretomic studies of TCR stimulated CTL: on day seven CTL were plated at a density of $1 \times 10^{6}$ live cells $/ \mathrm{ml}$ in serum free RPMI media (phenol red free, Thermo Fisher Scientific Gibco) supplemented with $50 \mu \mathrm{M}$ ß-mercaptoethanol (Sigma), InsulinTransferrin-Selenium 100× (ITS, Gibco) and $20 \mathrm{ng} / \mathrm{ml} \mathrm{IL-2} \mathrm{and}$ left to rest at $37^{\circ} \mathrm{C}$ with $5 \% \mathrm{CO}_{2}$ for $1 \mathrm{~h}$. CTL were then stimulated as described above for $4 \mathrm{~h}$ in the presence or absence of $10 \mu \mathrm{M}$ IC87114 inhibitor or $2 \mu \mathrm{M}$ PD184252 inhibitor or $1 \mu \mathrm{M}$ AKT inhibitor $1 / 2$ (Merck chemicals). DMSO was used as vehicle control. Supernatants were then collected, passed through a $0.22 \mu \mathrm{m}$ filter, snap frozen in liquid nitrogen and stored at $-80^{\circ} \mathrm{C}$ until further processing.

For ELISA: CTL were plated at a density of $1 \times 10^{6}$ live cells/ $\mathrm{ml}$ in complete RPMI media supplemented with $20 \mathrm{ng} / \mathrm{ml} \mathrm{IL-2}$ and left to rest at $37^{\circ} \mathrm{C}$ with $5 \% \mathrm{CO}_{2}$ for $1 \mathrm{~h}$ prior stimulation with $100 \mathrm{ng} / \mathrm{ml} \mathrm{gp33-41} \mathrm{peptide} \mathrm{added} \mathrm{to} \mathrm{the} \mathrm{supplemented}$ media for $4 \mathrm{~h}$ in the presence or absence of $10 \mu \mathrm{M}$ IC87114 inhibitor or $2 \mu \mathrm{M}$ PD184252 inhibitor or $1 \mu \mathrm{M}$ AKT inhibitor $1 / 2$. DMSO was used as vehicle control. Supernatants were collected, snap frozen in liquid nitrogen and stored at $-80^{\circ} \mathrm{C}$ until further processing.

-To generate CTL from FOXO1-GFP ${ }^{\mathrm{fl} / \mathrm{fl}} \mathrm{GzmB}$ cre+ mice (FOXO1-GFP KO) and control GzmB cre+ mice (WT), lymph nodes or spleens were used and single cell suspensions were prepared as described above. Cells were activated with $0.5 \mu \mathrm{g} / \mathrm{ml}$ anti-mouse CD3 (clone 145-2C11 Biolegend), $0.5 \mu \mathrm{g} / \mathrm{ml}$ antimouse CD28 (clone 37.51 eBioscience), in $10 \mathrm{ml}$ complete RPMI media supplemented with $20 \mathrm{ng} / \mathrm{ml} \mathrm{IL-2}$ and $2 \mathrm{ng} / \mathrm{ml} \mathrm{IL-12.} \mathrm{Cells}$ were activated for $48 \mathrm{~h}$, then washed out and cultured for a further five days in complete RPMI media supplemented with 20 $\mathrm{ng} / \mathrm{ml} \mathrm{IL-2}$ and $2 \mathrm{ng} / \mathrm{ml}$ IL-12.

For transcriptomic studies, on day six cells were plated at a density of $0.5 \times 10^{6}$ live cells/ml in complete RPMI media supplemented with $20 \mathrm{ng} / \mathrm{ml} \mathrm{IL-2} \mathrm{and} 2 \mathrm{ng} / \mathrm{ml} \mathrm{IL-12}$ and with or without $10 \mu \mathrm{M}$ IC87114 for $24 \mathrm{~h}$. DMSO was used as vehicle control. On day seven, media, containing all as above, was refreshed $2 \mathrm{~h}$ before cells were harvested and prepared for cell sorting.

-For FOXO1-GFP nuclear localisation: CTL from FOXO1$\mathrm{GFP}^{\mathrm{fl} / \mathrm{fl}} \mathrm{GzmB}$ cre- mice (expressing FOXO1-GFP tagged protein) were generated. Cells from WT mice (expressing untagged FOXO1 protein) were used as negative control for GFP expression. Spleens were used and single cell suspensions were prepared as described above. Cells were activated with 0.5 $\mu \mathrm{g} / \mathrm{ml}$ anti-mouse CD3, $0.5 \mu \mathrm{g} / \mathrm{ml}$ anti-mouse CD28, in $10 \mathrm{ml}$ complete RPMI media supplemented with $20 \mathrm{ng} / \mathrm{ml}$ IL-2 and 2 $\mathrm{ng} / \mathrm{ml} \mathrm{IL-12}$. Cells were activated for $48 \mathrm{~h}$, then washed out and cultured in complete RPMI media supplemented with $20 \mathrm{ng} / \mathrm{ml}$ IL-2. On days six or seven, cells were plated at a density of $1 \times 10^{6}$ live cells $/ \mathrm{ml}$ in the presence or absence of IC87114 inhibitor for $1 \mathrm{~h}(10 \mu \mathrm{M})$. DMSO was used as vehicle control.

\section{Cell Sorting}

Cell sorting was performed on a Sony SH800S cell sorter (Sony Biotechnology). Staining was performed in PBS supplemented with $1 \%$ FBS. Sorting and cells collection for ex vivo naïve $\mathrm{CD} 8^{+}$ $\mathrm{T}$ cells and $24 \mathrm{~h}$ TCR activated $\mathrm{CD}^{+} \mathrm{T}$ cell with or without inhibitor was performed in RPMI 1640 containing glutamine, supplemented with $1 \%$ FBS. Sorting and cell collection for FOXO1-GFP KO and WT CTL was performed in RPMI 1640 containing glutamine, supplemented with $10 \%$ FBS.

Fluorophore-conjugated antibodies were obtained from BD Biosciences, eBioscience or Biolegend.

-Ex vivo naïve $\mathrm{CD}^{+} \mathrm{T}$ cells were sorted as $\mathrm{DAPI}^{-}$ $\mathrm{TCR}^{+} \mathrm{CD}^{+} \mathrm{CD} 2 \mathrm{~L}^{\mathrm{hi}} \mathrm{CD} 44^{\text {lo }}$. $1 \mu \mathrm{g}$ Fc block (BD Pharmingen) per million cells was used to block FC receptors. Cells were then stained with the fluorophoreconjugated antibodies TCRß-PerCPCy5.5 (H57-587), CD4PECy7 (RM4-5), CD8-PE (53-6.7), CD44-APC (IM7), CD62L-FITC (MEL-14) and DAPI in PBS 1\% FBS.

$-24 \mathrm{~h}$ TCR activated CD8 ${ }^{+} \mathrm{T}$ cells with or without inhibitor were stained with the fluorophore-conjugated antibody CD8-APC and DAPI and sorted as $\mathrm{DAPI}^{-} \mathrm{CD} 8^{+}$.

-CTL FOXO1-GFP KO from FOXO1-GFP ${ }^{\mathrm{fl} / \mathrm{fl}} \mathrm{GzmB}$ cre+ mice were stained with the fluorophore-conjugated antibody CD8$\mathrm{APC}$ and DAPI and sorted as $\mathrm{DAPI}^{-} \mathrm{CD}^{+} \mathrm{GFP}^{-}$.

-CTL WT from GzmB cre+ mice were stained with the fluorophore-conjugated antibody CD8-APC and DAPI and sorted as $\mathrm{DAPI}^{-} \mathrm{CD} 8^{+}$.

All sorted cells were then washed twice with HBSS before being snap frozen in liquid nitrogen and stored at $-80^{\circ} \mathrm{C}$ until further processing.

\section{Forward/Side Scatter}

Forward and side scatter profiles for sorted WT CTL treated or untreated for $24 \mathrm{~h}$ with the PI3K p $110 \delta$ inhibitor were acquired on a FACSVerse using FACSuite software and data were analysed using FlowJo software version 10.6.1 (Treestar).

\section{Flow Cytometry Analysis of Nuclear Extract for FOX01-GFP Localisation}

Harvested cells were washed in PBS supplemented with 1\% FBS and then either not lysed or lysed in $300 \mu \mathrm{l}$ ice-cold nuclear extraction buffer (3.8 mM trisodium citrate, $9.6 \mathrm{mM} \mathrm{NaCl}, 0.05 \%$ 
NP-40). Total cells (used as control to show that PI3K p110 $\delta$ inhibition increases FOXO1 nuclear localisation but not the total level of FOXO1 protein) and the nuclei of lysed cells were then fixed immediately with $300 \mu \mathrm{l}$ ice-cold IC fixation buffer (eBioscience) for $15 \mathrm{~min}$ at $4^{\circ} \mathrm{C}$. After washing, nuclei were stained with DAPI. Samples were acquired on Novocyte (Acea Biosciences Inc.) using Novo Express software. Data analysis was performed using FlowJo software version 10.6.1 (Treestar).

\section{ELISA}

ELISA kits for GZMB, IFN $\gamma$ and TNF $\alpha$ (Invitrogen) were used according to the manufacturer's instructions to determine the effects of $4 \mathrm{~h}$ TCR stimulation and PI3K p110 $\delta$, MEK or AKT inhibitor treatments on the secretion of these proteins. Experiments were performed in biological triplicate. Statistical analysis was performed with Prism 7 for Mac OS X using unpaired, unequal variance t-test with Welch's correction. The $P$ values are considered as follow: ${ }^{\star} P<0.05,{ }^{\star \star} P<0.01$, ${ }^{\star * *} P$ $<0.001,{ }^{* * *} P<0.0001$, 'ns' not statistically significant.

\section{Western Blotting}

Cell pellets were lysed in RIPA buffer (100 mM HEPES, pH 7.4, $150 \mathrm{mM} \mathrm{NaCl}, 1 \% \mathrm{NP} 40,0.1 \%$ SDS, $0.5 \%$ sodium deoxycholate, 10\% glycerol, $1 \mathrm{mM}$ EDTA, $1 \mathrm{mM}$ EGTA, $1 \mathrm{mM}$ TCEP, and protease and phosphatase inhibitors (Roche)). Cell lysates were sonicated and then centrifuged at $4^{\circ} \mathrm{C}$ at $13,000 \mathrm{rpm}$ for $10 \mathrm{~min}$.

LDS sample buffer $(1 \times)$ (Life Technologies) and tris(2carboxyethyl)phosphine (TCEP, $25 \mathrm{mM}$ ) was added to the samples prior to incubation at $100^{\circ} \mathrm{C}$ for $10 \mathrm{~min}$. Samples were loaded and separated by SDS-PAGE (NuPAGE precast gels, Life Technologies), and then transferred to nitrocellulose membranes (Whatman). Blots were probed with the following antibodies: AKT p-S473 (Cell Signalling and Technology, \#4058), AKT pT308 (Cell Signalling and Technology, \#4056), AKT (Cell Signalling Technology, \#9272), SMC1 (Bethyl Laboratories, A300-055A), p44/42 MAPK p-T202/Y204, Cell Signalling and Technology, \#9106) and p44/42 MAPK (Cell Signalling and Technology, \#9102). Horseradish peroxidase (HRP)-conjugated secondary antibodies were used (Thermo Scientific). Chemiluminescence was measured using an Odyssey Fc Imaging System (Licor). Image Studio Software (LI-COR) was used to quantify chemiluminescence detected using the Odyssey system. Total protein bands were normalised to the corresponding SMC1 loading control, and then phosphorylated protein bands were normalised to the total protein band and normalised to a control sample (+TCR $4 \mathrm{~h}$ ). Statistical analysis was performed with Prism 7 for Mac OS X using unpaired, unequal variance t-test with Welch's correction. The $P$ values are considered as follow: ${ }^{\star} P<0.05,{ }^{* *} P<0.01$, ${ }^{\star * *} P<0.001,{ }^{* * *} P$ $<0.0001$, 'ns' not statistically significant.

\section{RNA Extraction for RNA-Sequencing (RNAseq)}

Total RNA was extracted from frozen cell pellets of sorted naïve $\mathrm{CD}^{+} \mathrm{T}$ cells and TCR activated with or without inhibitor, CTL either not TCR stimulated or TCR stimulated for $4 \mathrm{~h}$ in the presence or absence of inhibitor, and WT or FOXO1-GFP KO CTL with or without $24 \mathrm{~h}$ inhibitor treatment using Qiagen RNAeasy mini kit (Qiagen) as per manufacturer's instructions. Total RNA was quantified using a Nanodrop ND-1000 spectrophotometer. Three biological replicates were generated for each condition.

For naïve $\mathrm{CD}^{+} \mathrm{T}$ cells less than $1 \mu \mathrm{g}$ of total RNA was supplied; for TCR activated with or without inhibitor cells and all CTL samples $1 \mu \mathrm{g}$ of total RNA was supplied to the Finnish Functional Genomics Centre of Turku Biosciences whom prepared the libraries and performed the sequencing.

\section{RNA Libraries Preparation and HiSeq Sequencing Run Information}

The quality of the total RNA samples was inspected using Agilent Bioanalyzer 2100 or Advanced Analytical Fragment Analyzer and the concentration of the samples was measured with Nanodrop ND-2000 (Thermo Scientific) or Qubit Fluorometric Quantitation (Life Technologies). Libraries preparation was started from $300 \mathrm{ng}$ of total RNA using the Illumina TruSeq Stranded mRNA sample preparation kit (15031047) as per manufacturer's instructions. Data presented here were run as three independent experiments as follows: one lane for naïve/ TCR $24 \mathrm{~h}$ activated cells with or without inhibitor (naïve/TCR activated $24 \mathrm{~h} \pm$ inhibitor) (this lane included also an unpublished dataset not part of this manuscript); one lane for CTL unstimulated or TCR $4 \mathrm{~h}$ stimulated with or without inhibitors (Unstim/TCR stimulated $4 \mathrm{~h}$ CTL \pm inhibitors); and one lane for WT and FOXO1-GFP KO CTL with or without inhibitor for $24 \mathrm{~h}$ (WT/FOXO1-GFP KO CTL \pm inhibitor $24 \mathrm{~h}$ ).

The quality of the libraries was confirmed with Advanced Analytical Fragment Analyzer and the concentrations of the libraries were quantified with Qubit Fluorometric Quantitation (Life Technologies). Libraries were sequenced using Illumina HiSeq 3000 (naïve/TCR activated \pm inhibitor) or Illumina HiSeq 2500 (TCR stimulated CTL \pm inhibitors) or Illumina HiSeq 3000 (WT/FOXO1-GFP KO CTL \pm inhibitor) instruments using paired-end sequencing chemistry and 75 bp (naïve/TCR activated \pm inhibitor) or $100 \mathrm{bp}$ (TCR stimulated CTL \pm inhibitors) or $75 \mathrm{bp}$ (WT/FOXO1-GFP KO CTL \pm inhibitor) read length. The typical yields are $120-150 \times 10^{6}$ paired-end reads per lane on Illumina HiSeq 2500 and $260-310 \times 10^{6}$ paired-end reads per lane on Illumina HiSeq 3000.

\section{RNAseq Data Processing}

Naïve/TCR activated \pm inhibitor and TCR stimulated CTL \pm inhibitors: raw reads were first aligned against the Mus musculus mm10 reference genome using the STAR aligner (34) (versions 2.5.2b or 2.4.2a) and then associated with known genes using the RefSeq annotation. The number of reads associated with each gene was counted using subreads package (versions 1.5.1 and 1.5.0). Genome (Mus Musculus mm10) and reference gene annotations (RefSeq based annotation) were downloaded from Illumina iGenomes web site.

WT/FOXO1-GFP KO CTL \pm inhibitor: read quality was evaluated and confirmed using MultiQC (35). Raw reads were 
aligned to the GRCm38.p6 (Ensembl) build of the Mus musculus reference genome using the STAR aligner (34) (version 2.7.1a), with 'outFilterType BySJout' option to reduce the number of spurious junctions. The STAR quantMode GeneCounts option was used to map aligned reads to genes to generate a gene counts matrix, using the annotation file GRCm38.98 (Ensembl).

For all experiments, the noise from low count genes was reduced using the filterByExpr function. The resulting count matrix was normalised by the Trimmed Mean of M-values (TMM) method using the edgeR package $(36,37)$. EdgeR RPKM function was used on TMM-normalised counts to calculate FPKM values, with total exon length calculated using GenomicRanges (38) as the sum of the non-overlapping exonic regions for a gene.

Differential expression analysis was performed using Limma package (39). Reads were converted to $\log _{2}$ counts per million and precision weighted using the voom function. A linear model was fitted to each gene and empirical Bayes moderated t-statistics were applied. $P$ values were adjusted to control the global falsediscovery rate.

All scripts used to perform analysis are available from authors upon request.

\section{Statistics and Calculations RNAseq Data}

Genes were defined as differentially expressed if they had an adj. $P$ value $<0.05$ and a fold change $>2$ or $<0.5$ (Naïve/TCR activated \pm inhibitor and TCR stimulated CTL +/- inhibitors); and a fold change $>1.5$ or $<0.67$ (WT/FOXO1-GFP $\mathrm{KO} \pm$ inhibitor). ${ }^{\star}$ adj. $P<0.05$ and fold change $>2$ or $<0.5$ and fold change $>1.5$ or $<0.67$.

For the gene ontology (GO) Term enrichment analysis, GO terms enriched in the statistically significant changed gene were identified using the functional annotation tools within DAVID Bioinformatics Resources 6.8, NIAID/NIH (http://david.ncifcrf. gov). The top 5 GO terms describing "biological process" annotation were identified based on $P$ value and terms represented by $<3$ genes in the changed gene list were excluded from the analysis.

Heatmaps were generated using the Morpheus tool from the Broad Institute (http://software.broadinstitute.org/morpheus). Heatmap in Figure 2B was arranged with IFN $\gamma$ positioned at the top and with all mRNA ranked according to similarity using the nearest-neighbor analysis and Pearson correlation. Heatmap in Figure 2D was arranged with Aacs positioned at the top. The other heatmaps, with the exclusion of heatmaps in Figures 6F, G, were arranged with the indicated mRNA on the top and the others ranked according to similarity using the nearest-neighbor analysis and Pearson correlation. Heatmaps in Figures 6F, G were arranged following the order of Figures 3G, H.

Venn diagrams were generated using Venny 2.1 from BioinfoGP (http://bioinfogp.cnb.csic.es/tools/venny) (40).

\section{Proteomics Sample Preparation}

Cell pellets were lysed in $0.5 \mathrm{ml}$ urea lysis buffer ( $8 \mathrm{M}$ urea, 100 $\mathrm{mM}$ Tris $\mathrm{pH}$ 8.0, protease (cOmplete Mini EDTA-free, Roche) and phosphatase inhibitors (PhosSTOP, Roche) and vigorously mixed for $30 \mathrm{~min}$ at room temperature. Samples were sonicated with a Branson digital sonicator and protein concentration was determined by BCA assay as per manufacturer's instructions
(Thermo Fisher Scientific). Lysates were reduced with $10 \mathrm{mM}$ dithiothreitol (DTT) and incubated at $30^{\circ} \mathrm{C}$ for $30 \mathrm{~min}$ before being alkylated with $50 \mathrm{mM}$ iodoacetamide (IAA) in the dark at room temperature for $45 \mathrm{~min}$. Lysates were then diluted with tris buffer $\left(100 \mathrm{mM}\right.$ tris $\left.\mathrm{pH} 8.0,1 \mathrm{mM} \mathrm{CaCl}_{2}\right)$ to $4 \mathrm{M}$ urea. LysC (Wako), reconstituted in tris buffer, was added to the samples at a 50:1 (protein:LysC) ratio and incubated at $30^{\circ} \mathrm{C}$ overnight. Samples were then transferred to low-bind $15 \mathrm{ml}$ Falcon tubes (Eppendorf) and further diluted with tris buffer to $0.8 \mathrm{M}$ urea before trypsin (Promega), reconstituted with tris buffer, was added at a ratio of $50: 1$ protein/trypsin and incubated at $30^{\circ} \mathrm{C}$ for $8 \mathrm{~h}$. After digestion, samples were adjusted to $1 \%$ trifluoroacetic acid (TFA) prior desalting with C18 Sep-Pack cartridges (Waters). The cartridges were washed twice with $1 \mathrm{ml}$ elution buffer ( $50 \%$ acetonitrile ACN/0.1\%TFA) and equilibrated twice with $1 \mathrm{ml}$ wash buffer (0.1\% TFA). Acidified peptides were loaded twice and then washed three times with $1 \mathrm{ml}$ washing buffer. Peptides were eluted into Eppendorf Protein LoBind tubes by 2 elutions of $600 \mu \mathrm{l}$ elution buffer each and dried down in a SpeedVac (Genevac).

\section{Strong Anion Exchange Chromatography}

Dried peptide samples were resuspended in $210 \mu \mathrm{SAX}$ sample buffer (10 mM sodium borate-20\% (v/v) acetonitrile), $\mathrm{pH}$ was adjusted to $\mathrm{pH} 9.3$ with $1 \mathrm{M} \mathrm{NaOH}$ if necessary, and then fractionated with an UltiMate 3000 HPLC (high-performance liquid chromatography) system equipped with an AS24 SAX column. For the separation, the buffers used were $10 \mathrm{mM}$ sodium borate ( $\mathrm{pH}$ 9.3) (SAX buffer A) and $10 \mathrm{mM}$ sodium borate ( $\mathrm{pH}$ 9.3), $500 \mathrm{mM} \mathrm{NaCl}$ (SAX buffer B). An exponential elution gradient starting with Buffer A was used to separate the peptides into 16 fractions, which were collected and desalted with Sep-Pack C18 96well desalting plates (Waters). Desalted peptides were then dried down with a SpeedVac (Genevac). Dried fractions were then resuspended in $1 \%$ formic acid, and separated by nanoscale $\mathrm{C} 18$ reverse-phase chromatography (UltiMate 3000 RSLCnano System, Thermo Fisher Scientific) before being electrosprayed into the linear trap quadrupole-Orbitrap mass spectrometer (LTQ Orbitrap Velos Pro; Thermo Fisher Scientific) as described previously (22). The chromatography buffers used were as follows: HPLC buffer A $(0.1 \%$ formic acid), HPLC buffer B (80\% acetonitrile and $0.08 \%$ formic acid), and HPLC buffer C (0.1\% formic acid). Peptides were then loaded onto an Acclaim PepMap100 nanoViper C18 trap column (100 $\mu \mathrm{m}$ inner diameter, $2 \mathrm{~cm}$; Thermo Fisher Scientific) in HPLC buffer $\mathrm{C}$ with a constant flow of $5 \mu \mathrm{l} / \mathrm{min}$. After trap enrichment, peptides were eluted onto an EASY-Spray PepMap RSLC nanoViper, C18, $2 \mu \mathrm{m}, 100 \AA$ column $(75 \mu \mathrm{m}, 50 \mathrm{~cm}$; Thermo Fisher Scientific) using the following buffer gradient: $2 \% \mathrm{~B}$ (0 to $3 \mathrm{~min}$ ), 2 to $40 \% \mathrm{~B}$ (3 to $128 \mathrm{~min}$ ), 40 to $98 \%$ B (128 to $130 \mathrm{~min}$ ), $98 \% \mathrm{~B}$ (130 to $150 \mathrm{~min}$ ), 98 to $2 \% \mathrm{~B}$ (150 to $151 \mathrm{~min}$ ), and equilibrated in $2 \% \mathrm{~B}$ (151 to $180 \mathrm{~min}$ ) at a flow rate of $0.3 \mu \mathrm{l} / \mathrm{min}$. The eluting peptide solution was automatically electrosprayed into the coupled linear trap quadrupole-Orbitrap mass spectrometer (LTQ Orbitrap Velos Pro; Thermo Fisher Scientific) using an EASY-Spray nanoelectrospray ion source at $50^{\circ} \mathrm{C}$ and a source voltage of $1.9 \mathrm{kV}$ (Thermo Fisher Scientific). The mass spectrometer was operated in positive ion mode. Full-scan MS survey spectra 
(mass/charge ratio, 335 to 1,800 ) in profile mode were acquired in the Orbitrap with a resolution of 60,000. Data were collected using data-dependent acquisition (DDA): the 15 most intense peptide ions from the preview scan in the Orbitrap were fragmented by collision-induced dissociation (normalized collision energy, 35\%; activation Q, 0.250; activation time, $10 \mathrm{~ms}$ ) in the LTQ after the accumulation of 5,000 ions. Precursor ion charge state screening was enabled, and all unassigned charge states as well as singly charged species were rejected. The lock mass option was enabled for survey scans to improve mass accuracy. MS was performed by the Proteomics Facility, University of Dundee, UK.

\section{Processing and Analysis of Proteomic Data}

The data were processed, searched and quantified with the MaxQuant software package (version 1.6.10.43). Proteins and peptides were identified using a hybrid database from databases in Uniprot release 202006 as described in Marchingo et al. (41). The following search parameters were used: protein N-terminal acetylation, methionine oxidation, glutamine to pyroglutamate, and glutamine and asparagine deamidation were selected as variable modifications; carbamidomethylation of cysteine residues was set as a fixed modification; Trypsin and LysC were selected as the proteolytic enzymes; up to two missed cleavages were permitted; protein and PSM False discovery rates was set to 0.01 and matching of peptides between runs was switched off. Perseus software package (version 1.6.6.0) was used for data filtering and protein copy number quantification. Proteins were quantified from unique (found only in a specific protein group) and razor (peptides assigned to a specific protein group without being unique to that group) peptides. The data set was filtered to remove proteins categorised as "contaminants", "reverse" and "only identified by site". Copy numbers were calculated using the proteomic ruler plugin as described in Wisniewski et al. (42). Copy numbers of histones in a diploid mouse cell get assigned to the summed peptide intensities of all histones present in a sample. The ratio between the histone peptide intensity and the summed peptide intensities of the other identified proteins is then used to estimate copy number per cell for all identified proteins in the data set.

\section{Statistics and Calculations Proteomic Data}

Three biological replicates were generated. $P$ values were calculated via a two-tailed, unequal-variance t-test on $\log _{10}$ transformed copy number per cell values in Microsoft Excel. $P$ values $<0.05$ were considered as being statistically significant. Fold change $>2$ or $<0.5$ were considered as cut-off. Heatmaps were generated using the Morpheus tool from the Broad Institute (http://software.broadinstitute.org/morpheus). ${ }^{\star} P<0.05$ and fold change $>2$ or $<0.5$.

\section{Secretomics Sample Preparation}

For this experiment, $400 \mu \mathrm{l}$ of supernatant was used for each sample and peptides were generated using the S-Trap mini column method (Protifi). Briefly, samples were mixed on a shaker at $1,000 \mathrm{rpm}$ at room temperature for $5 \mathrm{~min}$ after addition of $10 \mathrm{mM}$ TCEP and 50
mM TEAB (Triethylammonium bicarbonate) and then transferred to a ThermoMixer shaking at $500 \mathrm{rpm}$ at $95^{\circ} \mathrm{C}$ for $5 \mathrm{~min}$ before being mixed again at $1,000 \mathrm{rpm}$ at room temperature for $5 \mathrm{~min}$. Samples were alkylated with $20 \mathrm{mM}$ Iodoacetamide (IAA) in the dark at room temperature for $1 \mathrm{~h}$ and protein concentration was determined using the EZQ method (Thermo Fisher Scientific) according to the manufacturer's instructions. Lysates were acidified by addition of $1.2 \%$ phosphoric acid and then mixed by vortexing. S-Trap binding buffer ( $90 \%$ methanol and $100 \mathrm{mM}$ TEAB pH 7.1) was added at a 1:7 ratio of lysate to S-Trap binding buffer, loaded on S-Trap mini columns (Protifi) and then centrifuged at 6,500 rpm for $30 \mathrm{~s}$. Bound protein was washed five times by addition of $400 \mu$ of S-Trap binding buffer and centrifugation at 6,500 rpm for $30 \mathrm{~s}$. Digestion buffer (125 $\mu \mathrm{l})$ containing trypsin in a ratio protein 1:trypsin 20 was added into the top of the column and incubated at $47^{\circ} \mathrm{C}$ for $2 \mathrm{~h}$ without shaking. Peptides were then eluted by addition and centrifugation of $80 \mu \mathrm{l}$ of digestion buffer, $80 \mu \mathrm{l}$ of $0.2 \%$ aqueous formic acid and $80 \mu \mathrm{l}$ of $50 \%$ aqueous acetonitrile containing $0.2 \%$ formic acid. Eluted peptides were dried down in a SpeedVac (Genevac) and then reconstituted in $5 \%$ formic acid by shaking at $1,000 \mathrm{rpm}$ at $30^{\circ} \mathrm{C}$ for $1 \mathrm{~h}$. Peptides were run on a Q Exactive Plus Hybrid Quadrupole-Orbitrap mass spectrometer (Thermo Fisher Scientific) as single shot in a datadependent acquisition (DDA) mode (120 min). MS was performed by the Proteomics Facility, University of Dundee, UK. The data were processed, searched and quantified as described above with only trypsin selected as proteolytic enzyme. Raw intensity for each replicate was normalised to the corresponding control and expressed as \% intensity relative to TCR. Statistical analysis was performed with Prism 7 for Mac OS X using unpaired, unequal variance t-test with Welch's correction. The $P$ values are considered as follow: ${ }^{\star} P<0.05$, ${ }^{* *} P<0.01,{ }^{* *} P<0.001,{ }^{* * *} P<0.0001$.

\section{RESULTS}

\section{PI3K p1108 Control of Antigen Receptor Transcriptional Programs in Naïve $\mathrm{CD}^{+} \mathrm{T}$ Cells}

TCR driven activation of naïve T cells is the key step in directing the differentiation of effector $\mathrm{T}$ cells. Therefore, to understand how PI3K p $110 \delta$ controls $\mathrm{CD}^{+} \mathrm{T}$ cell differentiation we first assessed the contribution of PI $3 \mathrm{~K}$ p $110 \delta$ signalling pathways to the transcriptional remodelling initiated by the TCR. The cell model used was P14 $\mathrm{CD}^{+} \mathrm{T}$ cells expressing a TCR specific for lymphocytic choriomeningitis virus (LCMV) glycoprotein peptide gp33-41. To define the PI3K p110 $\delta$ transcriptional programs we used RNA sequencing to examine the transcriptome of naïve $\mathrm{CD}^{+} \mathrm{T}$ cells before and after $24 \mathrm{~h}$ of activation with the LCMV glycoprotein peptide gp33-41 in the presence or absence of the selective PI3K p1108 inhibitor IC87114 (PI3Kdi). In these experiments we quantified 11,262 mRNA and using a fold change cut off $>2$ fold and adj. $P$ value $<0.05$ we saw that the abundance of 5,613 mRNA was modified by antigen receptor engagement (Figure 1A; Supplementary Table 1 and Supplementary Datasheet 1). There are a number of mRNA (2,722), which represent around $24 \%$ of the total transcriptome measured, that are expressed in naïve $\mathrm{T}$ cells and 
A

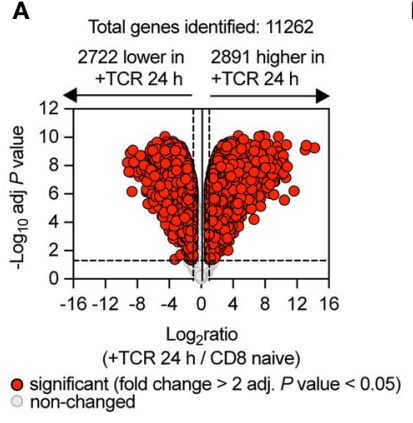

D

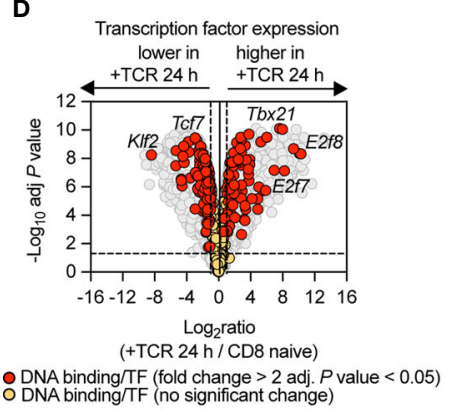

\begin{tabular}{|c|c|c|}
\hline \multicolumn{3}{|c|}{ Enriched GO terms for mRNA TCR induced in CD8 ${ }^{+} \mathrm{T}$ cells } \\
\hline Enriched GO term & Fold enrichment & $P$ value \\
\hline GO: $0006260 \sim$ DNA replication & 2.3 & $3.30 \times 10^{-14}$ \\
\hline GO: $0042254 \sim$ Ribosome biogenesis & 2.5 & $3.00 \times 10^{-13}$ \\
\hline GO: $0006364 \sim$ rRNA processing & 2.2 & $1.10 \times 10^{-12}$ \\
\hline GO: $0007049 \sim$ Cell cycle & 1.4 & $1.10 \times 10^{-08}$ \\
\hline GO: 0000278 Mitotic nuclear division & 1.6 & $4.00 \times 10^{-08}$ \\
\hline
\end{tabular}

C

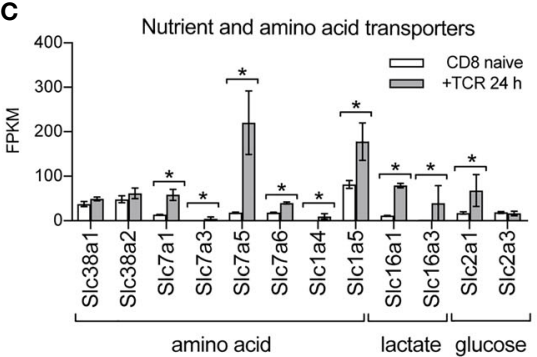

E

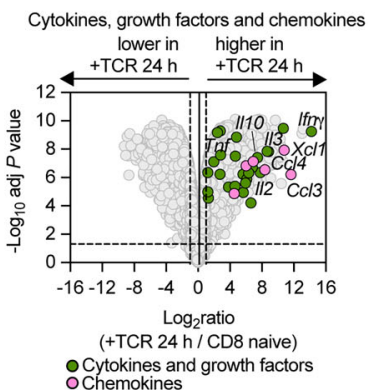

FIGURE 1 | Remodelling of $\mathrm{CD}^{+} \mathrm{T}$ cell transcriptome in response to immune activation. RNA sequencing was used to characterise the transcriptome of sorted ex vivo naiive or $24 \mathrm{~h}$ gp33-41 peptide activated (TCR) P14 CD8 ${ }^{+} \mathrm{T}$ cells. (A) Volcano plot of mRNA expression of $24 \mathrm{~h}$ TCR activated versus naiive CD8 ${ }^{+} \mathrm{T}$ cells. mRNA significantly different between the two populations (fold change $>2$ or $<0.5$; adj. P values $<0.05$ ) shown in red. The horizontal dashed lines indicate an adj. $P$ value of 0.05 shown as $-\log _{10}$ while vertical dashed lines indicate a fold change of 2 and 0.5 shown as $\log _{2}$. The vertical solid line indicates the mean of log 2 ratio. (B) Enrichment analysis for biological processes for mRNA whose expression was induced upon TCR activation. The top 5 processes are presented. (C) Expression profile (FPKM) of amino acid, lactate and glucose transporters. FPKM shown as the mean of three biological replicates \pm standard deviation. ${ }^{*}$ adj. P $<0.05$ and fold change $>2$ or $<0.5$. (D) Volcano plot highlighting changes in transcription factor expression in response to $24 \mathrm{~h}$ TCR activation (GO:0003700 DNA binding transcription factor activity). Annotated mRNA significantly different between the two populations compared are shown in red (fold change $>2$ or $<0.5$; adj. $P$ value $<0.05$ ). Transcription factors that showed no significant differences are shown in yellow. (E) Volcano plot highlighting mRNA expression of cytokines, growth factors and chemokines whose expression was induced in response to $24 \mathrm{~h}$ TCR activation (GO:0005125 Cytokine activity and GO:0008009 Chemokine activity).

Annotated cytokines and growth factors (green) and annotated chemokines (pink) that were significantly upregulated upon TCR stimulation (fold change $>2$ or $<0.5$; adj. $P$ value $<0.05)$. Input data for highlighted mRNA in (D, E) are listed in Supplementary Datasheet 1.

downregulated upon immune activation including mRNA encoding transcription factors which maintain pluripotency and cell quiescence (e.g. Klf2 and Tcf7), translational repressors such as $P d c d 4$ and growth factor receptors such as the $I l 7$ and Il6 receptors (Supplementary Table 1). There are also a large number of mRNA $(2,891)$, around $26 \%$ of the total transcriptome measured, whose abundance increases following immune activation and this includes mRNA encoding proteins annotated in a GO term enrichment analysis as cell cycle machinery and ribosomal biogenesis (Figure 1B and Supplementary Table 1) but also includes nutrient transporters (Figure 1C), transcription factors (Figure 1D) and a wide array of cytokines, growth factors and chemokines (Figure 1E).

What are the consequences of inhibiting PI3K p $110 \delta$ during TCR activation on the CD ${ }^{+} \mathrm{T}$ cell transcriptome? Overall, PI3K p $110 \delta$ inhibition controlled the expression of 670 mRNA ( $>2$ fold change threshold and an adj. $P$ value of $<0.05)$ in the TCR activated $\mathrm{CD}^{+} \mathrm{T}$ cells (Figure $2 \mathrm{~A}$ ), which represent $6 \%$ of the total 11,262 mRNA identified. There are 257 mRNA whose expression is repressed and more than 400 mRNA whose expression is increased by loss of PI3K p $110 \delta$ activity (Supplementary Table 2 and Supplementary Datasheet 1). The selectivity of the effects of PI3K p $110 \delta$ inhibition is striking as shown by Figure 2B which uses nearest neighbor analysis and Pearson correlation to group and align the expression profile of 11,262 mRNA in naïve, TCR activated $\mathrm{CD}^{+} \mathrm{T}$ cells and CD8 ${ }^{+} \mathrm{T}$ cells activated via their TCR in the presence of the PI3K p110 $\delta$ inhibitor. These data show that a large portion of the TCR regulated transcriptional programs is PI3K p110 $\delta$ independent. Of note, PI3K p $110 \delta$ does not mediate TCR induced changes in the abundance of transcripts encoding the metabolic machinery that mediate glycolysis, one carbon or fatty acid metabolism (Figures 2C, D and Supplementary Figure 1A). Moreover, 
TCR engagement switches on expression of the transcription factors Myc and Hif1 alpha (Hif1 $\alpha$ ), which control expression of amino acid transporters and glucose transporters (41, 43, 44) respectively, even in the absence of PI3K p $110 \delta$ activity (Figure 2E). Indeed expression of Hif $1 \alpha$ mRNA was increased relative to controls in cells activated in the absence of PI3K p110 $\delta$ activity. The selectivity of the effects of PI3K p $110 \delta$ signalling is also highlighted by exploring the impact on the expression of mRNA encoding key transcription factors that control $\mathrm{CD}^{+} \mathrm{T}$ cell differentiation: over 300 transcription factors were identified using the annotation DNA binding/transcription factor activity (GO:0003700) and only 31 are controlled by PI3K p110 (Figure 2F and Supplementary Datasheet 1). As examples, the ability of the TCR to downregulate expression of Klf2 and Tcf7 is

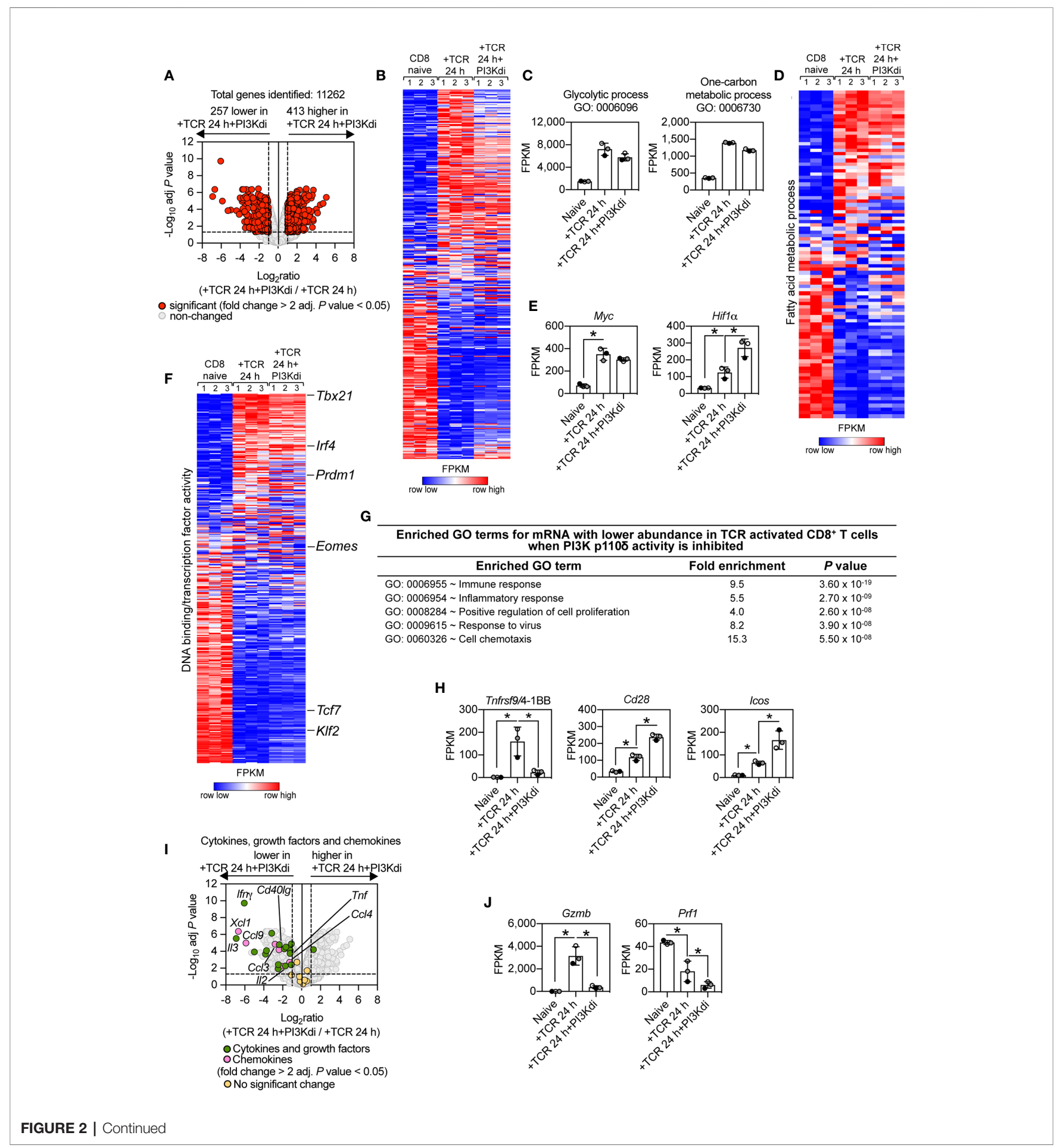




\begin{abstract}
FIGURE 2 | PI3K p110 $\delta$ control of antigen receptor transcriptional programs in naïve CD8 ${ }^{+} \mathrm{T}$ cells. P14 CD8 ${ }^{+} \mathrm{T}$ cells were activated in vitro with the gp33-41 peptide in the presence or absence of the PI3K p110 $\delta$ inhibitor IC87114 (PI3Kdi) for 24 h. (A) Impact of PI3K p110 $\delta$ inhibition on mRNA expression. Volcano plot shows the ratio of PI3K p110 $\delta$ treated versus untreated TCR activated CD8 ${ }^{+} \mathrm{T}$ cells. mRNA significantly different between the two populations (fold change $>2$ or <0.5; adj. $P$ values <0.05) shown in red. The horizontal dashed lines indicate an adj. $P$ value of 0.05 shown as - log $_{10}$ while vertical dashed lines indicate a fold change of 2 and 0.5 shown as $\log _{2}$. The vertical solid line indicates the mean of $\log _{2}$ ratio. (B) Heatmap of CD8 ${ }^{+} \mathrm{T}$ cells naïve, TCR activated $24 \mathrm{~h} \pm \mathrm{PI} 3 \mathrm{~K} \mathrm{p} 110 \delta$ inhibitor (PI3Kdi) transcriptomes. Heatmap was arranged with Ifn $\gamma$ positioned at the top and shows the relative mRNA abundance graded from low (blue) to high (red) per row. Input data for the heatmap are listed in Supplementary Datasheet 1. (C) Summed mRNA expression (FPKM) of genes annotated as glycolytic process (GO:0006096), and one-carbon metabolic process (GO:0006730). FPKM represented as the mean of three biological replicates \pm standard deviation. Input data are listed in Supplementary Datasheet 1. (D) Heatmap of mRNA encoding enzymes that mediate fatty acid metabolism (Fatty acid metabolic process GO:0006631). The heatmap shows the relative mRNA abundance graded from low (blue) to high (red) per row. Input data for the heatmap are listed in

Supplementary Datasheet 1. (E, H, J) mRNA expression levels (FPKM) of Myc, Hif1 $\alpha$, Tnfrsf9/4-1BB, Cd28, Icos, Gzmb and Prf1. FPKM shown as the mean of three biological replicates \pm standard deviation. * adj. $\mathrm{P}<0.05$ and fold change $>2$ or $<0.5$. (F) Heatmap of more than 300 mRNA annotated as DNA binding/ transcription factor activity or added manually (GO:0003700). Heatmap was arranged with Tbx21 mRNA positioned at the top and shows the relative mRNA abundance graded from low (blue) to high (red) per row. Input data for the heatmap are listed in Supplementary Datasheet 1. (G) Enrichment analysis for biological processes for mRNA whose expression was reduced in TCR activated CD8 ${ }^{+} \mathrm{T}$ cells by PI3K p110 $\delta$ inhibition. The top 5 processes are presented. (I) Volcano plot highlighting the effect of PI3K p110 $\delta$ inhibition on mRNA expression of cytokines, growth factors and chemokines induced in response to $24 \mathrm{~h}$ TCR activation (GO:0005125 Cytokine activity and GO:0008009 Chemokine activity). Shown in green are annotated cytokines and growth factors and shown in pink are annotated chemokines that were significantly regulated in response to PI3K p110 $\delta$ inhibition (fold change $>2$ or <0.5; adj. P value <0.05). Cytokines, growth factors and chemokines that showed no significant differences are shown in yellow. Input data are listed in Supplementary Datasheet $\mathbf{1}$
\end{abstract}

not PI3K p110 $\delta$ dependent. Nor does PI3K p110 $\delta$ inhibition prevent TCR induction of Tbx21, Blimp1 and Irf4: key drivers of $\mathrm{CD}^{+} \mathrm{T}$ cell differentiation (Figure $2 \mathrm{~F}$ and Supplementary Figure 2A). Nevertheless, there are some key $\mathrm{CD}^{+} \mathrm{T}$ cell transcription factors whose expression is PI3K p $110 \delta$ dependent including Eomes (Figure 2F and Supplementary Figure 2A). There are also increases in expression of mRNA encoding the transcriptional repressors $\mathrm{BACH} 2$ and ID2 in PI3K p110 $\delta$ inhibitor treated cells (Figure 2F and Supplementary Figure 2A).

What are the PI3K p110 $\delta$ controlled processes in T cells? Here GO term enrichment analysis reveals the dominant effect of PI3-kinase signalling pathways in TCR activated cells is to control expression of transcripts annotated as 'immune response molecules' (Figure 2G). For example, TCR triggering induces an increase in expression of mRNA encoding the important $\mathrm{T}$ cell costimulatory molecules $4-1 \mathrm{BB}, \mathrm{CD} 28$ and ICOS: TCR mediated upregulation of mRNA encoding 4-1BB is dependent on PI3K p110 $\delta$; whereas Icos and Cd28 mRNA is increased in PI3K p110 $\delta$ inhibitor treated cells (Figure 2H).

Antigen activation also causes $\mathrm{T}$ cell to switch on expression of mRNA encoding a diverse array of cytokines, chemokines and cytotoxic effector molecules. These include Interleukin-2 (IL-2), Interferon gamma (IFN $\gamma$ ), Tumour necrosis factor (TNF), Interleukin-3 (IL-3), Interleukin-24 (IL-24), Lymphotoxinalpha (LT $\alpha)$, Leukemia inhibitory factor (LIF), CD40 ligand (CD40lg), Chemokine (C-C motif) ligand 3 (CCL3), Chemokine (C-C motif) ligand 4 (CCL4), Chemokine (C motif) ligand 1 (XCL1). The induction of this subset of mRNA is all dependent on activation of PI3K p110 $\delta$ (Figure 2I). The expression of mRNA encoding effector $\mathrm{CD}^{+} \mathrm{T}$ cell cytolytic molecules like granzymes and perforin also depends on PI3K p110 $\delta$ activity in TCR activated $\mathrm{CD}^{+} \mathrm{T}$ cells (Figure 2J).

PI3K p110 $\delta$ activation thus both positively and negatively controls the expression of $\mathrm{T}$ cell costimulatory molecules and is required for the production of multiple cytokines and effector molecules that allow $\mathrm{CD}^{+} \mathrm{T}$ cells to mediate adaptive immune responses. It is particularly striking that PI3K p $110 \delta$ activity is required for the production of CCL3, CCL4 and XCL1 as these are the essential chemokines used by immune activated $\mathrm{CD} 8^{+} \mathrm{T}$ cells to direct their interactions with dendritic cells/monocytes and macrophages $(45,46)$.

\section{PI3K p1108 Control of Transcriptional Programs in Effector Cytotoxic CD8 $^{+}$T Cells}

The TCR-PI3K p110 $\delta$ signalosome is remodelled during T cell differentiation (47) but the contribution of PI3K p110 $\delta$ to TCR triggered transcriptional programs in effector $\mathrm{CD}^{+} \mathrm{T}$ cells has not been assessed. To address this question, antigen-primed P14 TCR transgenic $\mathrm{CD}^{+} \mathrm{T}$ cells were clonally expanded in IL-2 to produce differentiated CTL. RNA sequencing then compared the transcriptome of CTL before and after retriggering of the TCR with the LCMV glycoprotein peptide gp33-41 in the presence or absence of the PI3K p110 $\delta$ inhibitor IC87114. The data show that out of 11,022 mRNA, TCR triggering induces increased expression of 1,039 mRNA and downregulated expression of 1,294 mRNA (fold change cut off $>2$ and an adj. $P$ value $<0.05$ ), representing just over $20 \%$ of the total transcriptome measured (Figure 3A; Supplementary Table 3 and Supplementary Datasheet 2). The upregulated mRNA in TCR activated CTL encode cytokines, growth factors and chemokines highlighting how one key role of antigen receptor triggering in effector $\mathrm{T}$ cells is to produce molecules that communicate pathogen recognition to other cells of the immune system (Figures 3B, C). The downregulated mRNA in TCR activated CTL encode genes annotated in a GO term enrichment analysis as "cell cycle" (Figure 3D) that includes E2F transcription factors (E2f1-E2f2E2f7-E2f8), cyclin A2 (Ccna2), cyclin B2 (Ccnb2) and cyclin D3 (Ccnd3) (Supplementary Figures 3A, B).

As in the naive $\mathrm{T}$ cells, only a small fraction (less than $3 \%$ ) of the TCR induced transcriptional programs is sensitive to inhibition of PI3K p $110 \delta$ in CTL. Blocking PI3K p $110 \delta$ activity decreased expression of approximately 185 mRNA and increased the abundance of 78 mRNA (Figure 3E, Supplementary Table 4 and Supplementary Datasheet 2). Enrichment analysis of the downregulated mRNA revealed that the top 3 enriched GO 
terms for PI3K $\mathrm{p} 110 \delta$ sensitive processes are biological processes involving cytokines and chemokines (Figures 3F-H). Figure 3G thus shows that PI3K p $110 \delta$ activity is required for the production of mRNA encoding multiple cytokines including Granulocyte-macrophage colony-stimulating factor (GM-CSF/ CSF2), IL-2, TNF, IL-3, IL-24, IL-10, Lto, CD40lg. Notably, PI3K p $110 \delta$ activity is also required for the TCR induced production of chemokine mRNA including CCL9 and XCL1 (Figure 3H).
Moreover, the effects of PI3K p110 $\delta$ inhibition on expression of mRNA encoding chemokines and cytokines were paralleled by changes in the production of cytokine and chemokine proteins as measured by high resolution mass spectrometry analysis of the proteomes and secretomes of unstimulated or P14 CTL activated with cognate peptide for $4 \mathrm{~h}$ in the presence or absence of the PI3K p $110 \delta$ inhibitor (Figure 3I and Supplementary Datasheet 4).

A

Total genes identified: 11022

1294 lower in 1039 higher in

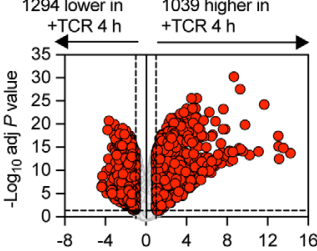

$\log _{2}$ ratio

(+TCR $4 \mathrm{~h} /$ Unstimulated CTL)

significant (fold change $>2$ adj. $P$ value $<0.05$ )
non-changed

C

Cytokines, growth factors and chemokines
lower in higher in

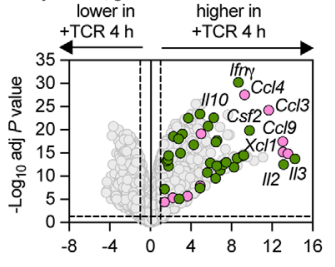

$$
\log _{2} \text { ratio }
$$

(+TCR $4 \mathrm{~h} /$ Unstimulated CTL) OCytokines and growth factors
OChemokines

\section{$\mathbf{F}$} Enriched GO terms for mRNA with lower abundance when PI3K p1100 activity is \begin{tabular}{l}
\multicolumn{1}{c}{ Enriched GO term } \\
\hline GO: $0006955 \sim$ Immune response \\
GO: $0006954 \sim$ Inflammatory response \\
GO: $0007267 \sim$ Cell-cell signaling \\
GO: $0070374 \sim$ Positive regulation of ERK1 and ERK2 \\
cascade \\
GO: $0007275 \sim$ Multicellular organism development
\end{tabular}

H

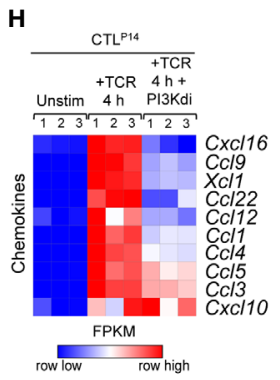

\begin{tabular}{lcc}
\hline \multicolumn{3}{c}{ Enriched GO terms for mRNA TCR induced in CTL } \\
\hline \multicolumn{1}{c}{ Enriched GO term } & Fold enrichment & $P$ value \\
\hline GO: $0006955 \sim$ Immune response & 4.8 & $7.10 \times 10^{-27}$ \\
GO: 0006954 Inflammatory response & 4.2 & $4.20 \times 10^{-26}$ \\
GO: $0007165 \sim$ Signal transduction & 2 & $1.70 \times 10^{-10}$ \\
GO: $0070374 \sim$ Positive regulation of & 3.8 & $1.90 \times 10^{-10}$ \\
ERK1 and ERK2 cascade & & $3.20 \times 10^{-09}$ \\
GO: $0008284 \sim$ Positive regulation of cell & proliferation
\end{tabular}

\begin{tabular}{lcc}
\hline \multicolumn{3}{c}{ Enriched GO terms for mRNA TCR repressed in CTL } \\
\hline Enriched GO term & Fold enrichment & $\boldsymbol{P}$ value \\
\hline GO: 0007049 Cell cycle & 2 & $3.50 \times 10^{-14}$ \\
GO: 0006260 DNA replication & 3.3 & $2.70 \times 10^{-12}$ \\
GO: 0035458 Cellular response to & 5 & $1.60 \times 10^{-09}$ \\
interferon-beta & 1.9 & $1.80 \times 10^{-07}$ \\
GO: 0051301 Cell division & 5.5 & $3.60 \times 10^{-07}$
\end{tabular}

E

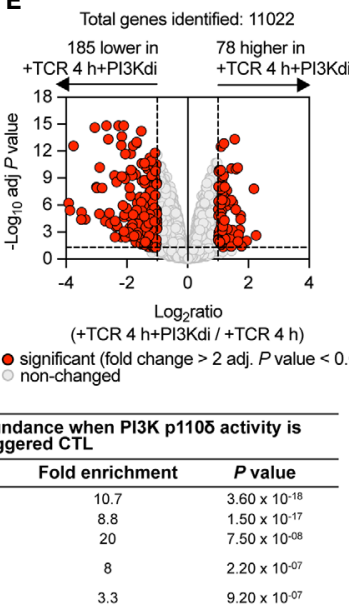

G $\mathrm{CTL}^{\mathrm{P} 14}$

Unstim $4 \mathrm{~h}$ Pl3Kdi

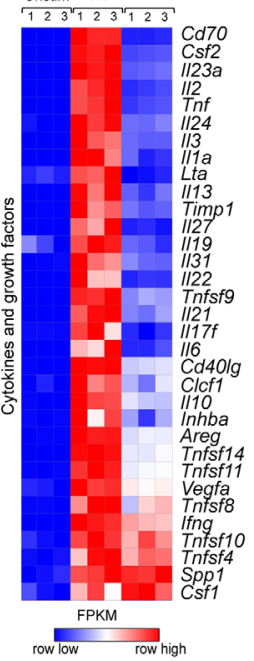

I PROTEOMICS

J 20,000 Gzmb
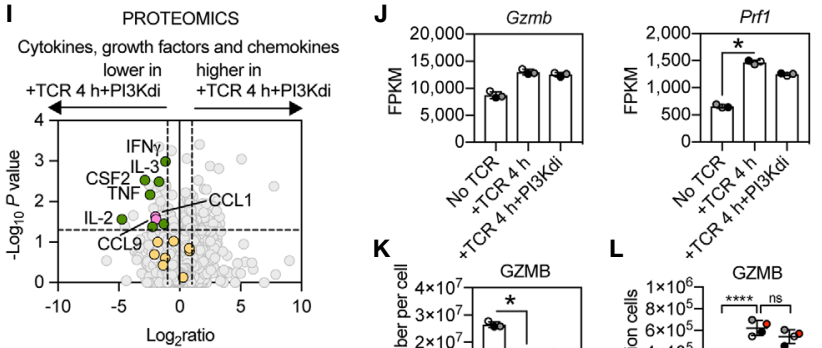

(+TCR $4 \mathrm{~h}+$ PI3Kdi / +TCR $4 \mathrm{~h}$ )

Cytokines and growth factors

(fold change $>2 P$ value $<0.05$ ) ONo significant change
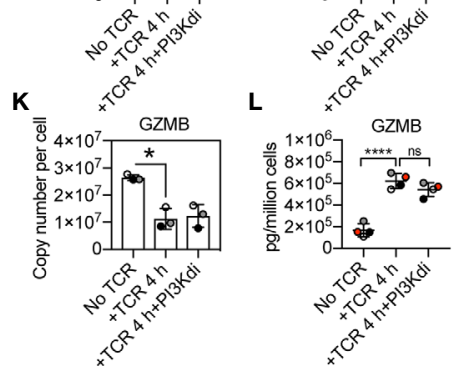

FIGURE 3 | Continued 


\begin{abstract}
FIGURE 3 | PI3K p110 $\delta$ control of antigen receptor transcriptional programs in effector cytotoxic CD8 ${ }^{+} \mathrm{T}$ cells. P14 CTL were either left unstimulated or TCR retriggered with the LCMV peptide in the presence or absence of the PI3K p110 $\delta$ inhibitor IC87114 (PI3Kdi) for $4 \mathrm{~h}$ and the transcriptome analysed by RNAseq. (A) Impact of TCR retriggering on mRNA expression in CTL. Volcano plot showing the ratio for $4 \mathrm{~h}$ TCR retriggered versus unstimulated CTL. mRNA significantly different between the two populations (fold change $>2$ or $<0.5$; adj. $P$ values $<0.05$ ) shown in red. The horizontal dashed lines indicate an adj. $P$ value of 0.05 shown as $-\log _{10}$ while vertical dashed lines indicate a fold change of 2 and 0.5 shown as $\log _{2}$. The vertical solid line indicates the mean of log 2 ratio. (B, D) GO term enrichment analysis for biological processes for mRNA whose expression was up or downregulated by TCR retriggering. The top 5 processes are presented. (C) Volcano plot of cytokines, growth factors and chemokines mRNA whose expression was induced in CTL by 4 h TCR retriggering (GO:0005125 Cytokine activity and GO:0008009 Chemokine activity). Annotated cytokines and growth factors (green) and annotated chemokines (pink) that were significantly upregulated upon TCR retriggering (fold change $>2$ or $<0.5$; adj. $P$ value $<0.05$ ). Input data are listed in Supplementary Datasheet 2. (E) Volcano plot showing the ratio of TCR stimulated CTL \pm PI3K p110 $\delta$ inhibitor (PI3Kdi). In red mRNA significantly different between the two populations (fold change $>2$ or $<0.5$; adj. $P$ values $<0.05$ ). The horizontal dashed lines indicate an adj. $P$ value of 0.05 shown as $-\log _{10}$ while vertical dashed lines indicate a fold change of 2 and 0.5 shown as $\log _{2}$. The vertical solid line indicates the mean of $\log _{2}$ ratio. (F) Enriched GO terms for mRNA whose expression was reduced in TCR retriggered CTL in the absence of PI3K p110 $\delta$ activity. The top 5 biological processes are presented. (G, H) Heatmaps of mRNA encoding (G) cytokines, growth factors and (H) chemokines annotated as Cytokine activity (GO:0005125) and Chemokine activity (GO:0008009). The heatmaps show the relative mRNA abundance graded from low (blue) to high (red) per row. Input data for heatmaps are listed in Supplementary Datasheet 2. (I) The proteome of P14 CTL either left unstimulated or TCR retriggered for $4 \mathrm{~h}$ in the presence or absence of the PI3K p110 $\delta$ inhibitor IC87114 (PI3Kdi) was analysed by mass spectrometry. Volcano plot shows fold change in protein copy number between TCR retriggered CTL lacking PI3K p110 activity and TCR retriggered CTL, highlighting the effect of PI3K p110 inhibition on the expression of TCR induced cytokine, growth factor and chemokine proteins. In green annotated cytokines and growth factors and in pink annotated chemokines that were significantly regulated in response to PI3K p110 $\delta$ inhibition (fold change $>2$ or $<0.5$; $P$ value $<0.05$ ). In yellow cytokines, growth factors and chemokines that showed no significant changes. Input data are listed in Supplementary Datasheet 4 (J) mRNA expression levels (FPKM) of Gzmb and Prf1. FPKM shown as the mean of three biological replicates \pm standard deviation. *adj. P $<0.05$ and fold change $>2$ or <0.5. (K) Mean protein copy number per cell of granzyme B (GZMB) calculated using the proteomic ruler method as described in Materials and Methods. ${ }^{*}<0.05$ and fold change $>2$ or <0.5. (L) Granzyme B levels in supernatants of P14 CTL unstimulated and TCR retriggered in the presence or absence of PI3K p110 $\delta$ inhibitor (PI3Kdi) determined by ELISA. Data shown as the mean of four biological replicates \pm standard deviation and statistical analysis calculated by unpaired, unequal variance t-test with Welch's correction. The $P$ values are considered asfollow: ${ }^{\star \star \star \star} P<0.0001$ and 'ns' not statistically significant.
\end{abstract}

In TCR activated naïve T cells, PI3K p110 $\delta$ activity directed expression of the cytolytic effector molecules granzyme $\mathrm{B}$ and perforin (Figure 2J). mRNA and protein levels for these effector molecules are already high in CTL (Figure 3J) [Supplementary Figure $\mathbf{4 A}$ and (48)] However, neither granzyme nor perforin expression is PI3K p $110 \delta$ regulated in CTL (Figure 3J). Here, an important consideration is that a primary function of TCR engagement in CTL is to induce degranulation of cytolytic effector molecules. TCR activated CTL thus lose intracellular granzyme B protein following TCR engagement (Figure 3K). This response is not prevented by PI3K p110 $\delta$ inhibition, with the same amount of granzyme B content remaining in the cell in CTL after $4 \mathrm{~h}$ retriggering with or without inhibitor (Figure 3K). Analysis of granzyme B levels in cell supernatants also failed to see an impact of PI3K p110 $\delta$ inhibition on granzyme B exocytosis (Figure 3L). PI3K p110 $\delta$ thus does not control the TCR mediated production of cytolytic T cell granules or degranulation processes in CTL.

\section{The Impact of Sustained Loss of PI3K p1108 Activity on CTL Transcriptional Programs}

In these initial CTL experiments we examined the impact of PI3K p $110 \delta$ inhibition on an immediate $(4 \mathrm{~h})$ response of CTL to TCR engagement. The rationale for this time choice was that CTL activated via the TCR undergo activation induced cell death making it difficult to interpret data from longer time points. However, to explore further how PI3K p110 controls CTL biology, we also examined the impact of sustained inhibition of PI3K p $110 \delta$ on CTL phenotypes. In this context, CTL maintained in IL-2 have high levels of $\operatorname{PtdIns}(3,4,5) P_{3}$ produced by sustained activity of PI3K p110 $(6,7)$. RNA sequencing was thus used to compare the transcriptome of CTL maintained for $24 \mathrm{~h}$ in the presence or absence of the PI3K p110 $\delta$ inhibitor IC87114. In this setting, blocking PI3K p $110 \delta$ activity did not affect the growth and death of effector
$\mathrm{CD}^{+} \mathrm{T}$ cells [Figures $4 \mathrm{~A}, \mathrm{~B}$ and (23)] but did modulate the CTL transcriptome. Figure 4C shows increased expression of 254 mRNA and decreased expression of 96 mRNA in CTL lacking PI3K p $110 \delta$ activity (Supplementary Table 5 and Supplementary Datasheet 3). The mRNA dependent on sustained PI3K p110 $\delta$ activity in CTL includes chemokines and cytokines (Figure 4D). Interestingly, there is no PI3K p110 $\delta$ regulation of mRNA encoding the costimulatory molecules 4-1BB and ICOS (Figure 4E) or mRNA encoding cytolytic effector molecules granzyme and perforin (Figure 4F).

The absence of any effect of PI3K p $110 \delta$ inhibition on expression of cytolytic effector molecules and 4-1BB and ICOS is a fundamental difference between naïve $\mathrm{T}$ cells and CTL (Figures 2H, $\mathbf{J}$ and Figures 4E, F). One other difference, in terms of the impact of PI3K p110 $\delta$ inhibition on TCR responses in naïve T cells versus CTL, is the magnitude of the effects. There are many more TCR regulated transcripts dependent on PI3K p $110 \delta$ activity in naïve T cells than in CTL (Figure 4G).

What are the PI3K p $110 \delta$ regulated mRNA in CTL? The GO term annotation for mRNA that increased in expression following loss of PI3K p $110 \delta$ activity in CTL identified molecules linked to the control of cell adhesion and migration, notably CD62L (Sell) an adhesion molecule that controls T cell trafficking into secondary lymphoid tissue and Ccr7 and sphingosine 1-phosphate receptor 1 (S1pr1), chemokine receptors that regulates lymphocyte entry and egress from lymphoid tissues (Figures $\mathbf{4 H}$, I, and Supplementary Table 5). These have previously been described as proteins whose expression is controlled by PI3K p110 $\delta(29,49)$. mRNA that increases in expression in CTL treated with the PI $3 \mathrm{~K}$ p $110 \delta$ inhibitor also include the interleukin 7 receptor $(I l 7 r)$ and the transcription factors Tcf7 and Klf2 (Figure 4I and Supplementary Table 5).

Are there any new insights about the role of PI3K p110 $\delta$ in effector $\mathrm{CD}^{+} \mathrm{T}$ cells from these experiments? One fundamental observation is that sustained loss of PI3K p $110 \delta$ activity in CTL 
A

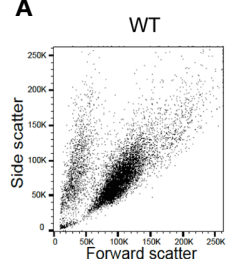

D
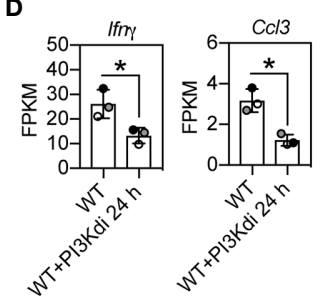

$\mathbf{F}$

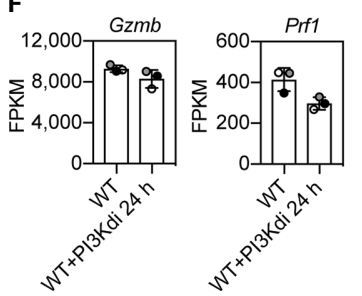

WT+

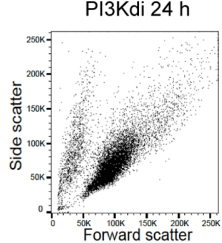

B
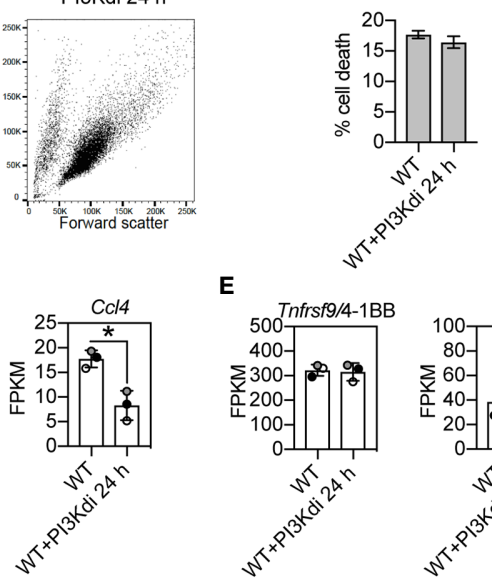

E

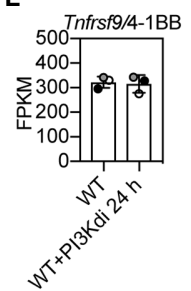

C

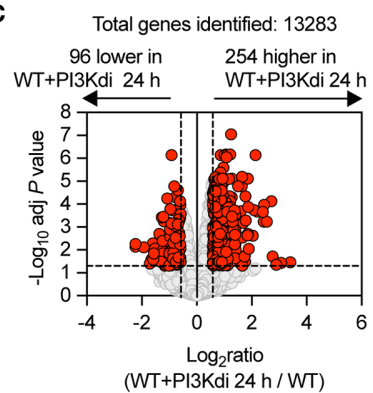

o significant (fold change $>1.5$ adj. $P$ value $<0.05$ ) non-changed
G

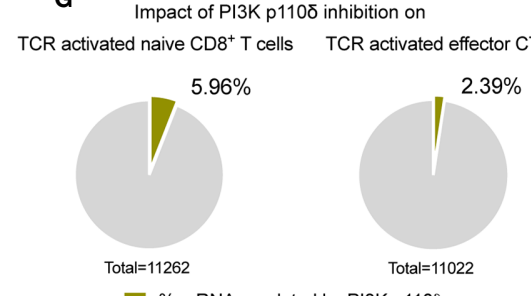

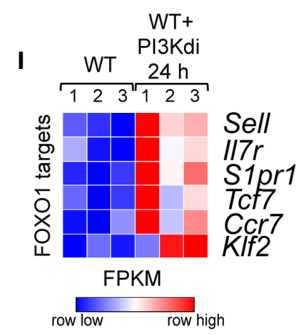

H

\begin{tabular}{lcc}
\hline \multicolumn{3}{c}{ Enriched GO terms for mRNA with higher abundance in CTL during sustained } \\
inhibition of PI3K p110 activity
\end{tabular}

$\mathbf{L}$
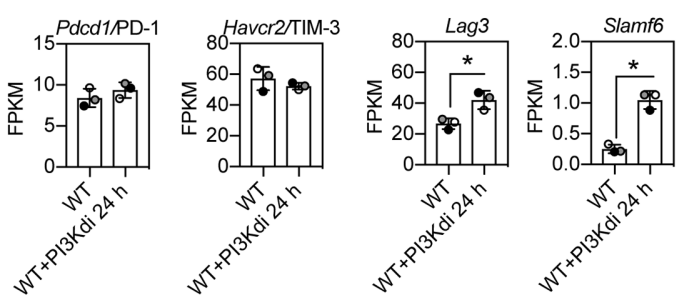

K

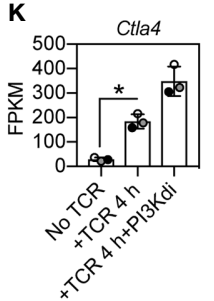

FIGURE 4 | Impact of sustained PI3K p110 8 inhibition on CTL transcriptional programs. WT CTL were maintained for $24 \mathrm{~h}$ in the presence or absence of the PI3K p1108 inhibitor IC87114 (PI3Kdi) and RNAseq was used to characterise their transcriptome. (A) Forward/side scatter flow cytometry analysis of IL-2/IL-12 maintained or $24 \mathrm{~h}$ inhibitor treated WT CTL. (B) Percentage of cell death at the end of the culture quantified by flow cytometry as proportion of cells DAPI positive. (C) Volcano plot showing the ratio for $24 \mathrm{~h}$ PI3K p1108 inhibitor (PI3Kdi) treated cells versus untreated WT CTL. mRNA significantly different between the two populations shown in red (fold change $>1.5$ or $<0.67$; adj. $P$ values $<0.05$ ). The horizontal dashed lines indicate an adj. $P$ value of 0.05 shown as $-\log _{10}$ while vertical dashed lines indicate a fold change of 1.5 and 0.67 shown as $\log _{2}$. The vertical solid line indicates the mean of $\log _{2}$ ratio. (D-F) Histograms showing mRNA expression levels (FPKM) for Ifn $\gamma, C C / 3, C c / 4$, Tnfrsf9/4-1BB, Icos, Gzmb and Prf1. FPKM shown as the mean of three biological replicates \pm standard deviation. (G) Percentage of the impact of PI3K p1108 inhibition on the total transcriptome of TCR activated naïve (left) and effector CD8 ${ }^{+} \mathrm{T}$ cells (right). (H) GO term enrichment analysis for biological processes for mRNA whose expression was induced by sustained inhibition of PI3K p110 $\delta$ activity. The top 5 processes are presented. (I) Heatmap of known FOXO1 targets in WT CTL cultured for $24 \mathrm{~h}$ in the presence or absence of PI3K p1108 inhibitor (PI3Kdi): Sell, II7r, S1pr1, Tcf7, Ccr7 and Klf2. The relative mRNA abundance is graded from low (blue) to high (red) per row. Input data for the heatmap are listed in Supplementary Datasheet 3. (J, K) mRNA expression levels (FPKM) of Ctla4 in (J) WT CTL \pm PI3K p1108 inhibitor (PI3Kdi) for $24 \mathrm{~h}$ and (K) in TCR stimulated CTL \pm PI3K p1108 inhibitor (PI3Kdi) for $4 \mathrm{~h}$. FPKM shown as the mean of three biological replicates \pm standard deviation. (L) mRNA expression levels (FPKM) for inhibitory receptors Pdcd1/PD-1, Havcr2/TIM-3, Lag3 and Slamf6 in WT CTL \pm PI3K p1108 inhibitor (PI3Kdi). (D, J, K, L): *adj. P <0.05 and fold change $>1.5$ or $<0.67$. 
increases mRNA expression of the important inhibitory receptor Ctla4 (Figure 4J). Increased Ctla4 expression was also seen in TCR activated CTL treated with the PI3K p110 $\delta$ inhibitor for $4 \mathrm{~h}$ (Figure 4K). In this respect other critical inhibitory receptors that control CTL function are PD-1, LAG3, TIM3 and SLAMF6: there is no effect of PI3K p $110 \delta$ inhibition on the mRNA expression of PD-1 or TIM3 but the mRNA expression of LAG3 and SLAMF6 is induced by loss of PI3K p110 $\delta$ activity (Figure 4L). These results inform that the activation of PI3K p $110 \delta$ represses the expression of three important inhibitory receptors: Ctla4, Slamf6 and Lag3 in CTL.

\section{The Contribution of PKB/AKT, FOXO1 and ERK1/2 to the Control of Cytokine and Chemokine Production in CTL}

One major role for PI3K p110 $\delta$ in CTL is to control the nuclear localisation of the transcription factor FOXO1. CTL have high levels of PtdIns $(3,4,5) P_{3}$ which drives phosphorylation and activation of the serine/threonine kinase AKT which phosphorylates FOXO1 causing its nuclear exclusion. Inhibition of PI3K p1108, which prevents PtdIns $(3,4,5) P_{3}$ production and AKT phosphorylation, causes a rapid translocation of FOXO1 to the nucleus [Figure 5A and (6)]. Here, a pertinent point is that the PI3K p110 $\delta$ repression of CD62L, CCR7, S1P1R, IL7R, TCF7 and KLF2 is mediated by FOXO1 $(29,49)$. A key question then is whether the repressive effect that PI3K p110 $\delta$ activity has on the expression of Ctla4, Slamf6 and Lag3 mRNA in CTL is mediated by FOXO1. In this context, it has been described that the expression of $\mathrm{PD}-1$ in $\mathrm{CD}^{+} \mathrm{T}$ cells is FOXO1 mediated (28) but the role of FOXO1 in controlling expression of other inhibitory receptors in CTL has not been examined.

To explore the mechanisms used by PI3K p110 $\delta$ to control T cells we analysed the impact of PI3K p $110 \delta$ inhibition on the expression of mRNA encoding CTLA4, SLAMF6, PD-1, TIM-3 and LAG3 in FOXO1 null CTL (FOXO1-GFP KO). To delete Foxo1 in CTL we backcrossed mice with floxed Foxo1-EGFP alleles (32) to transgenic mice expressing Cre recombinase under the control of a granzyme $\mathrm{B}$ promoter that allows deletion of FOXO1-GFP in CTL (Figure 5B, Supplementary Figures 5A, B). In normal CTL $>90 \%$ of FOXO1 is excluded from the nucleus and hence is transcriptionally inactive, whereas in CTL treated with the PI3K p110 $\delta$ inhibitor FOXO1 relocates to the nucleus. We therefore performed RNA sequencing of FOXO1-GFP null CTL before and after $24 \mathrm{~h}$ treatment with the PI3K p110 $\delta$ inhibitor and compared to WT treated CTL (Supplementary Datasheet 3). The full list of FOXO1 dependent mRNA identified in these experiments is shown in supplemental data (Supplementary Table 6) and includes previously identified FOXO1 targets including Tcf7, Klf2 and S1pr1 and as well as the transcription factor Hifla (Figure 5C). There were also mRNAs whose expression was enhanced in FOXO1 null CTL (Figure 5C). These data also show that the expression of Ctla4 and Slamf6 mRNA is dependent on FOXO1 (Figure 5D). In this respect, recent chromatin analysis (ChIP-seq) has identified FOXO1 binding to Ctla4 and Slamf6 gene loci and ATAC-seq analytic comparisons of wild type and FOXO1 null $\mathrm{CD}^{+} \mathrm{T}$ cells have indicated reduced chromatin accessibility in the Ctla4 and Slamf6 gene loci in FOXO1 null $\mathrm{CD}^{+} \mathrm{T}$ cells [Supplementary Figure 6A and (50)].
Interestingly, not all inhibitory receptor mRNA expression was changed in FOXO1 null CTL. Figure 5D shows Lag3 mRNA is still expressed in FOXO1 null CTL, though it is marginally lower, and PD-1 and TIM-3 are not regulated by PI3K p110 $\delta$ or FOXO1 (Figure 5D). It is also pertinent that not all the PI3K p110 $\delta$ regulated mRNA in CTL are sensitive to FOXO1 deletion (Figure 6A; Supplementary Table 7 and Supplementary Datasheet 3). For example, inhibition of PI3K p110 $\delta$ in CTL causes decreased expression of chemokine $(\mathrm{Ccl} 3, \mathrm{Ccl} 4)$ and cytokine $(I f n \gamma)$ mRNA in both WT and FOXO1 null T cells (Figure 6B). In this respect, previous studies have shown that the nuclear exclusion of FOXOs is necessary for the production of Interferon gamma (23), which would be consistent with a repressive role for FOXO1 in the control of Interferon gamma production. The current data found no evidence for enhanced expression of Interferon gamma mRNA in FOXO1 null CTL (Figure 6B), which highlights that the regulation of this key cytokine is not controlled by a simple FOXO1 dependent switch but requires coordination with other signalling pathways. It also argues that the profound effect of $\mathrm{PI} 3 \mathrm{~K}$ p $110 \delta$ on Interferon gamma production is not mediated solely by PI3K p $110 \delta$ control of FOXOs. In this respect, CTL lacking PI3K p $110 \delta$ activity show reduced activation of the MAP kinases ERK1 and ERK2 in response to antigen receptor engagement [Figure 6C, Supplementary Figure 7A and $(29,30)$ ]. This is germane because the activity of ERK1/2 is necessary for cytokine and chemokine production by antigen activated naïve $\mathrm{CD}^{+} \mathrm{T}$ cells (51). We therefore evaluated the PKB/AKT and ERK1/ 2 signalling requirements of antigen receptor induced cytokine and chemokine production in CTL. The data show that TCR induced production of multiple chemokines and cytokines is dependent on both the activation of the $\mathrm{PKB} / \mathrm{AKT}$ serine threonine kinases and ERK1/2 activity (Figures 6D, E). In particular the PI3K p110 $\delta$ controlled cytokines and chemokines mRNA, shown in Figures 3G, $\mathbf{H}$ and protein in Figure 3I, are also ERK1/2 controlled (Figures 6F-I, Supplementary Figure 8A, Supplementary Tables 8, 9 and Supplementary Datasheets 2, 4). These data collectively highlight that PI3K p110 $\delta$ control of the $\mathrm{CD}^{+} \mathrm{T}$ cell transcriptional programs reflects the role of this lipid kinase in coordinating the activity of multiple signalling pathways.

\section{DISCUSSION}

The aim of the present study was to gain an in-depth knowledge of the contribution of PI3K p $110 \delta$ to antigen receptor controlled programs in naïve and effector $\mathrm{CD} 8^{+} \mathrm{T}$ cells to understand how this lipid kinase controls $\mathrm{CD}^{+} \mathrm{T}$ cell differentiation. One important conclusion is that the dominant targets for PI $3 \mathrm{~K}$ p $110 \delta$ regulation are the secreted molecules and cell surface receptors that mediate $\mathrm{CD}^{+} \mathrm{T}$ cells communication with other immune cells. The production of multiple cytokines by TCR activated $\mathrm{CD}^{+} \mathrm{T}$ cells thus requires PI3K p $110 \delta$ activity. Notable amongst these are cytokines that control the activation of monocytes and macrophages such as GM-CSF/CSF2, TNF and IFN $\gamma$. One other important insight is that $\mathrm{PI} 3 \mathrm{~K}$ p110 $\delta$ controls the production of chemokines mRNA which orchestrate the ability of $\mathrm{CD} 8^{+} \mathrm{T}$ cells to recruit innate immune cells to sites of infection $(45,52)$. 

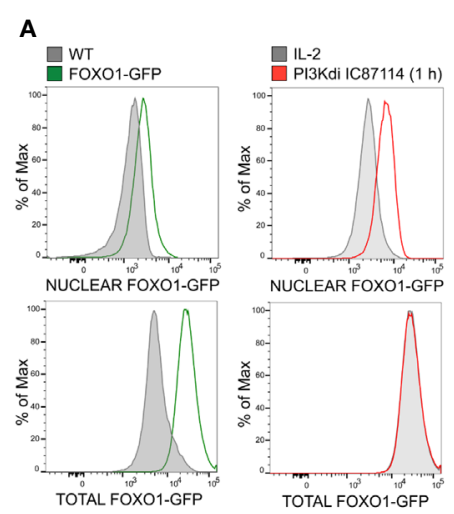

B

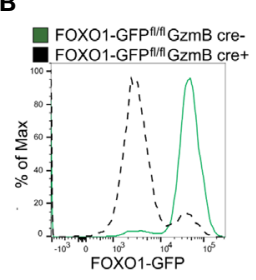

C
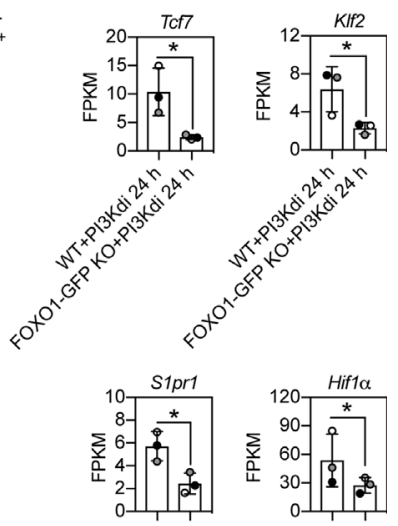

D
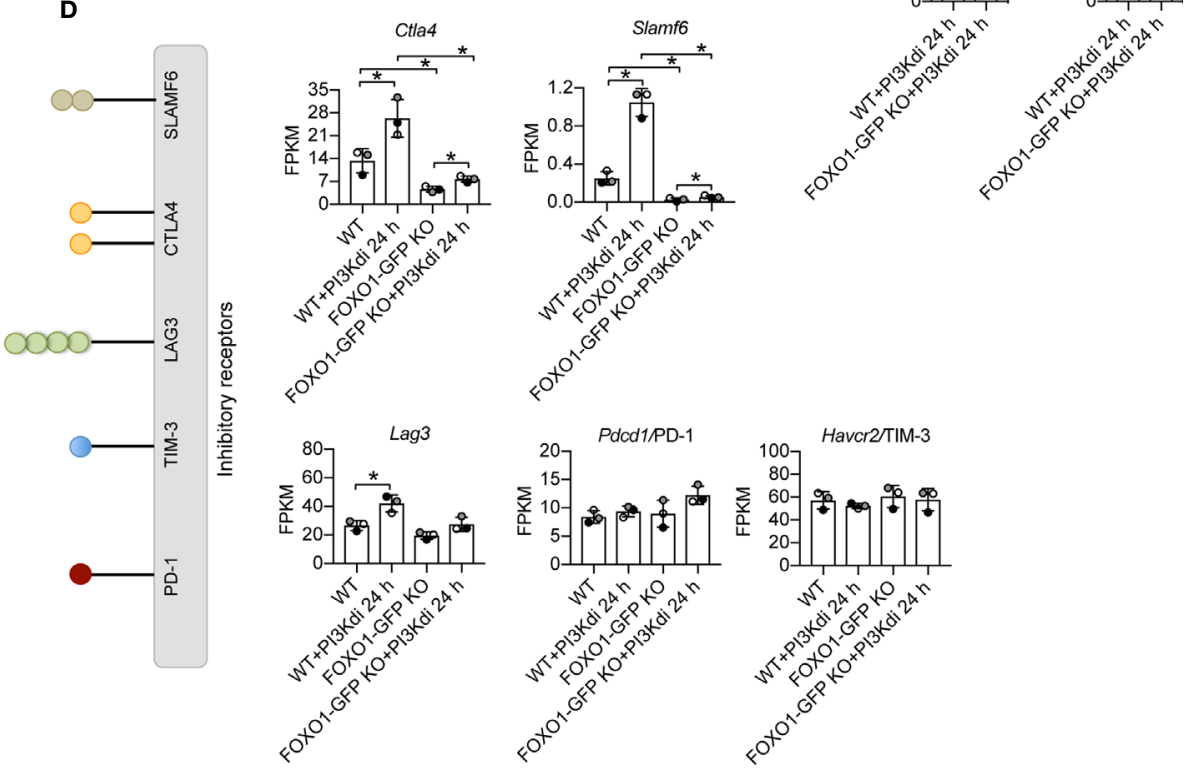

FIGURE 5 | Ctla4 and Slamf6 mRNA are modulated by FOXO1 in CTL. FOXO1-GFP null and WT CTL maintained for $24 \mathrm{~h}$ in the presence or absence of the PI3K p110 inhibitor IC87114 (PI3Kdi) were subjected to RNAseq and their transcriptomes compared. (A) Nuclear localisation of FOXO1-GFP analysed by flow cytometry in IL-2 maintained CTL and after $1 \mathrm{~h}$ treatment with the PI3K p1108 inhibitor. Left panel: purified nuclei from WT CTL (expressing untagged FOXO1) and FOXO1-GFP CTL were compared. The green line indicates detection of FOXO1-GFP expression level in the nucleus (top) or total cell (bottom). Right panel: purified nuclei (top) or total cells (bottom) from FOXO1-GFP CTL either maintained in IL-2 (grey filled line) or treated with PI3K p1108 inhibitor for $1 \mathrm{~h}$ (red line) were compared. The right shift of the red line compared to the grey filled line indicates an increased level of FOXO1-GFP in the nuclei of PI3K p110 $\delta$ inhibitor treated cells (top right), while there is no change in the total FOXO1 protein level (bottom right). Graph of treated cells is representative of three biological replicates. (B) Representative histogram showing the deletion of FOXO1-GFP quantified by flow cytometry in CTL generated from FOXO1-GFP ${ }^{f / f l}$ GzmB cre+ (grey dashed line FOXO1-GFP KO) versus FOXO1-GFPfl/fl GzmB cre- (green solid line FOXO1-GFP) mice. (C) mRNA expression levels (FPKM) of Tcf7, Klf7, S1pr1 and Hif1 $\alpha$ in WT and FOXO1-GFP KO CTL lacking PI3K p1108 activity. (D) Histograms showing mRNA expression levels (FPKM) for inhibitory receptors Ctla4, Slamf6, Lag3, Pdcd4/PD-1 and Havcr2/TIM3 in WT and FOXO1-GFP KO CTL \pm PI3K p1108 inhibitor (PI3Kdi). (C, D) FPKM shown as the mean of three biological replicates \pm standard deviation. ${ }^{*}$ adj. P $<0.05$ and fold change $>1.5$ or $<0.67$.

PI3K p110 $\delta$ activity also selectively shapes the repertoire of costimulatory receptor that control $\mathrm{CD} 8^{+} \mathrm{T}$ cell differentiation. For example, in naïve $\mathrm{CD} 8^{+} \mathrm{T}$ cells, TCR induced upregulation of the mRNA encoding the costimulatory receptor $4-1 \mathrm{BB}$, which is essential for the persistence of tissue resident $\mathrm{CD}^{+}$effector/ memory $\mathrm{T}$ cells $(53-55)$, is dependent on PI3K p110 activity. Further support for the concept that PI $3 \mathrm{~K}$ p $110 \delta$ controls the ability of $\mathrm{CD}^{+} \mathrm{T}$ cells to communicate with other immune cells includes the role of PI3K p110 in controlling expression of the inhibitory receptors Ctla4 and Slamf6 mRNA in effector CTL. Hence the loss of PI3K p110 $\delta$ activity and the relocalisation of the transcription factor FOXO1 to the nucleus upregulates Ctla4 and Slamf6 mRNA expression. The significance of this result stems from the essential role that CTLA4 and SLAMF6 have as immunomodulatory/ inhibitory receptors that restrain peripheral $\mathrm{T}$ cell responses to maintain peripheral tolerance (56-58). In this context, an elegant study by Kaech and colleagues has shown that FOXO1 is necessary for the differentiation of PD- $1^{\text {hi }}$ Eomes ${ }^{\text {hi }}$ terminally exhausted CTL. Moreover, FOXO1 null cytotoxic T cells fail to persist and control chronic viral infection (28). The authors hypothesised that the 
A

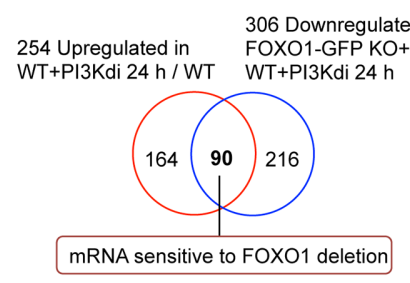

B

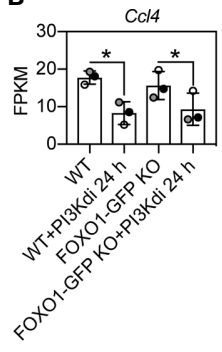

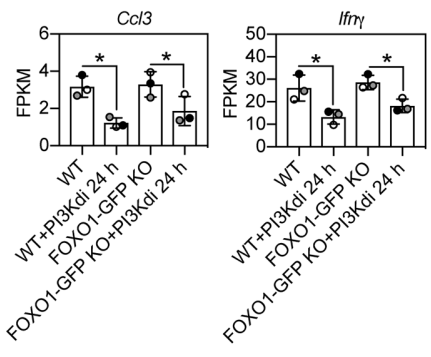

D

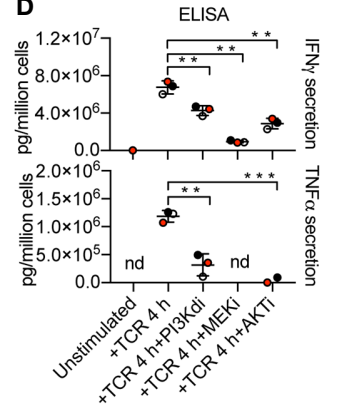

E

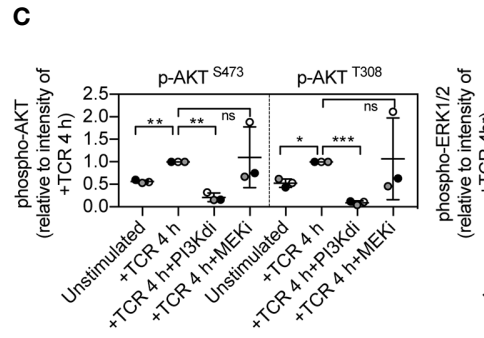

c
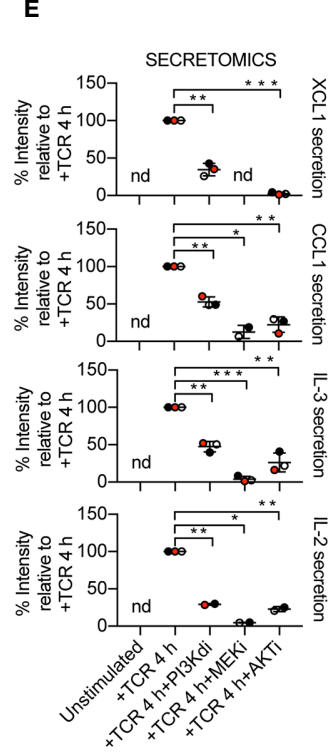

F

CTL + TCR $\begin{aligned} & +\mathrm{TCR}+\mathrm{TCR} \\ & 4 \mathrm{~h}+4 \mathrm{~h}+\end{aligned}$

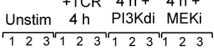

G

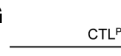

+ TCR + TCR Unstim
TCR
$4 \mathrm{~h}$
P PIKKdi MEKK
H PROTEOMICS

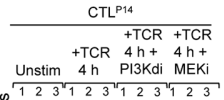

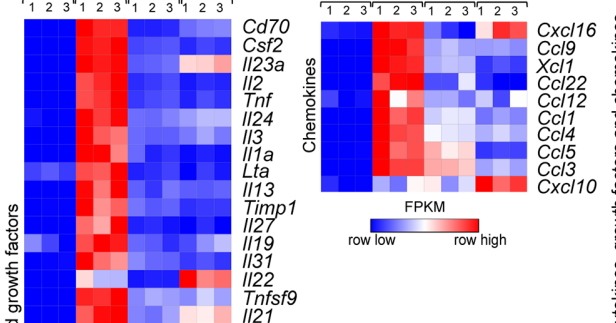

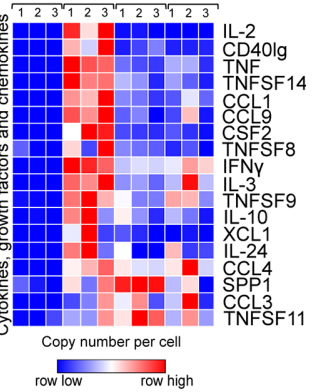

I

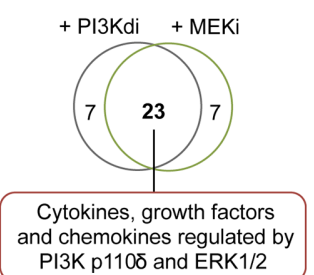

FIGURE 6 | Contribution of PKB/AKT, FOXO1 and ERK1/2 to the control of cytokine and chemokine production in CTL. (A) Venn diagram showing the overlap in the number of mRNA whose expression was induced by sustained PI3K p1108 inhibition in WT CTL and reduced in treated FOXO1-GFP KO CTL versus WT treated CTL. (B) mRNA expression levels (FPKM) of CC/4, CC/3 and Ifn $\gamma$ in WT and FOXO1-GFP KO CTL \pm PI3K p1108 inhibitor. *adj. P $<0.05$ and fold change $>1.5$ or $<0.67$. (C) Quantification of phosphorylated AKT (S473 and T308) and ERK1/2 (T202/Y204) in CTL in response to TCR stimulation in the presence or absence of PI3K p1108 (PI3Kdi) or MEK (MEKi) inhibitor assayed by western blot (Supplementary Figure 7A). (D) Levels of Interferon gamma (IFN $\gamma$ ) and Tumour necrosis factor alpha (TNF $\alpha$ ) present in the supernatant of P14 CTL unstimulated and TCR retriggered in the presence or absence of either PI3K p1108 (PI3Kdi), MEK (MEKi) or AKT (AKTi) inhibitor determined by ELISA. (E) Levels of XCL1, CCL1, IL-3 and IL-2 protein secreted in the supernatant of unstimulated, TCR stimulated and TCR stimulated CTL in the presence of either PI3K p1108 (PI3Kdi), MEK (MEKi) or AKT (AKTi) inhibitor assayed by mass spectrometry. Transcriptome and proteome of P14 CTL unstimulated and TCR retriggered in the presence or absence of either PI3K p1108 (PI3Kdi) or MEK (MEKi) inhibitor were characterised by RNAseq and mass spectrometry respectively. Impact of PI3K p110 and ERK1/2 inhibition on TCR induced cytokines and chemokines mRNA and protein expression was assessed. (F, G) Heatmaps showing mRNA encoding for annotated (F) cytokines, growth factors and (G) chemokines (Cytokine activity GO:0005125 and Chemokine activity GO:0008009). (H) Heatmap of proteins annotated as cytokines, growth factors and chemokines. Heatmaps show the relative mRNA abundance or the relative protein abundance graded from low (blue) to high (red) per row. Input data for heatmaps are listed in Supplementary Datasheets 2 (F, G) and $\mathbf{4}$ (H) (I) Overlap in the number of cytokine, growth factor and chemokine mRNA regulated by both PI3K p110 $\delta$ and ERK1/2. Data in (C-E) shown as the mean of three biological replicates \pm standard deviation and statistical analysis is calculated by unpaired, unequal variance t-test with Welch's correction. The $P$ values are considered as follow: ${ }^{\star} P<0.05,{ }^{\star \star} P<0.01,{ }^{\star \star \star} P<0.001,{ }^{\star \star \star \star} P<0.0001$. 'ns' not statistically significant. 
importance of FOXO1 in controlling T cell exhaustion reflected that FOXO1 controlled expression of the inhibitory receptor PD-1 (28). The current study forces a revision of this conclusion by demonstrating that FOXO1 does not directly control PD-1 expression in $\mathrm{CD}^{+} \mathrm{T}$ cells. Hence inhibition of PI3K p110 $\delta$, which immediately causes FOXO1 to relocalise to the nucleus to transcriptionally reprogram CTL, does not impact PD-1 expression. Moreover, there is no loss of PD-1 expression in FOXO1 null CD8 ${ }^{+}$ $\mathrm{T}$ cells. The expression of inhibitory receptors is thus not a simple on/off FOXO1 switch but requires integration of multiple signals with evidence that the oxygen environment is particularly important (59). In terms of $\mathrm{T}$ cell exhaustion and the ability of PI3K p $110 \delta$ to control $\mathrm{CD}^{+}$effector/memory $\mathrm{T}$ cells transition then FOXO1 control of Ctla4 and Slamf6 mRNA could be relevant as these two molecules control $\mathrm{T}$ cell exhaustion $(26,60,61)$. However, the role of FOXO1 in enforcing $\mathrm{T}$ cell quiescence by controlling expression of Tcf7, Klf2 and AP-1 family transcription factors will also be important in regulating the effector/memory versus senescent fate of $\mathrm{CD}^{+} \mathrm{T}$ cells (50). Moreover, PI3K p110 $\delta$ and FOXO1 control of $\mathrm{T}$ cell trafficking, by regulating the expression of key adhesion receptors and chemokine receptors, will also influence $\mathrm{CD}^{+} \mathrm{T}$ cell immune responses in vivo as will PI3K p110 $\delta$ control of the production of inflammatory cytokines and chemokines that recruit and/or regulate innate immune cells.

One salient insight from the current work is the magnitude and selectivity of the effects of PI3K p $110 \delta$ on the transcriptional restructuring that accompanies $\mathrm{T}$ cell differentiation. Hence only $6 \%$ of the TCR regulated transcripts in naïve T cells were sensitive to loss of PI3K p $110 \delta$ activity and in CTL this dropped to $3 \%$.

One notable result was that expression of the major regulatory components of the metabolic programs that control $\mathrm{T}$ cell growth and differentiation are not dependent on PI3K p $110 \delta$ activation. In this respect, $\mathrm{T}$ cell metabolic programs are controlled by the transcription factor Myc and serine/threonine kinase mTORC1 (mammalian target of rapamycin complex 1) (41, 48). We have shown previously that $\mathrm{PI} 3 \mathrm{~K}$ p $110 \delta$ activation is not required for mTORC1 activity in $\mathrm{CD}^{+} \mathrm{T}$ cells $(29,43)$ and the present data found no role for PI3K p110 $\delta$ in Myc mRNA expression or in controlling expression of Myc targets. Nor did PI3K p110 $\delta$ prevent expression of Hif $1 \alpha$ mRNA in $\mathrm{CD}^{+} \mathrm{T}$ cells. In this respect, analysis of the impact of mTORC1 inhibition of CTL transcriptome identified mRNA encoding glycolytic regulators and molecules that control lipid metabolism and ribosome biogenesis as major targets for mTORC1 signalling pathways (7) whereas the data herein show these were not regulated directly by

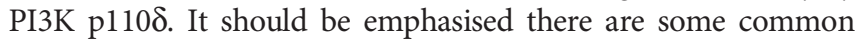
targets for $\mathrm{mTORC} 1$ and $\mathrm{PI} 3 \mathrm{~K}$ p $110 \delta$ notably KLF2 and receptors such as CD62L and S1PR1 that control T cell trafficking $(7,29,43)$. The existence of these shared targets has historically been explained using a linear model whereby PI3K p $110 \delta$ controls T cell responses via mTORC1 (29). However, it is now recognised that a shared requirement for PI3K p $110 \delta$ and mTORC1 activity rather reflects that these signalling molecules control pathways that can converge on a single target (43). Indeed, one key observation herein is that even the role of PI3K p $110 \delta$ in controlling $\mathrm{T}$ cell transcriptomes cannot be ascribed to a simple linear signalling pathway. For example, the ability of PI3K p110 $\delta$ to control the nuclear exclusion of FOXO1 is critical for $\mathrm{T}$ cell differentiation yet PI $3 \mathrm{~K}$ p $110 \delta$ and $\mathrm{PKB} / \mathrm{AKT}$ dependent but FOXO1 independent mechanisms are also relevant. As well the ability of PI3K p $110 \delta$ to repress the activity of ERKs can also contribute to its ability to modulate $\mathrm{T}$ cell differentiation.

Finally, a fundamental finding from the present study was that there are differences in how PI3K p $110 \delta$ inactivation impacts T cell antigen receptor activated lymphocytes as they exit quiescence versus effects in effector T cells. Effector CTL are thus far less sensitive to loss of PI3K p110 $\delta$ activity than naïve $\mathrm{T}$ cells. Moreover, inhibition of PI3K p110 $\delta$ could affect the expression of cytolytic effector molecules such as the granzymes and perforin in TCR activated naïve CD8 ${ }^{+}$T cells but not in CTL. PI3K p110 $\delta$ inhibition could also selectively suppress the production of cytokines and chemokines in both naïve T cells and CTL but did not prevent degranulation and release of cytolytic molecules by CTL. These results are pertinent because when thinking of how to use PI3K p110 $\delta$ inhibitors therapeutically it is important to consider whether the objective is to supress the effector immune response or to prevent de novo immune activation. Many screens focus on how inhibitors prevent primary activation of quiescent peripheral blood derived T cells. The current study highlights how unbiased screening of both naïve and effector populations would give a better perspective on the potential therapeutic benefit of signalling inhibitors.

\section{DATA AVAILABILITY STATEMENT}

The datasets presented in this study can be found in online repositories. The names of the repository/repositories and accession number(s) can be found below: https://www.ncbi.nlm. nih.gov/geo/, GSE169436; https://www.ncbi.nlm.nih.gov/geo/, GSE169449; https://www.ncbi.nlm.nih.gov/geo/, GSE169572; http://www.proteomexchange.org/, PXD025046; http://www. proteomexchange.org/, PXD025061. ChIP-seq, and ATAC-seq datasets were previously published (50) and deposited to the NCBI GEO/SRA and can be accessed with the identifier GSE163723.

\section{ETHICS STATEMENT}

The animal study was reviewed and approved by the University Ethical Review Committee under the authorisation of the UK Home Office Animals (Scientific Procedures) Act 1986.

\section{AUTHOR CONTRIBUTIONS}

LS and DC designed the experiments. LS, AN, and MD performed the experiments. JM did the bioinformatics for the RNAseq data. LS analysed the data and produced the figures. LS and DC interpreted the results and wrote the manuscript. DC conceived the study, supervised the experiments and provided financial support. All authors contributed to the article and approved the submitted version. 


\section{FUNDING}

This research was supported by a Wellcome Trust Principal Research Fellowship to DC (205023/Z/16/Z). JM was supported by an Australian NHMRC CJ Martin Early Career fellowship and JM and DC have received funding from the European Union's Horizon 2020 research and innovation programme under the Marie Sklodowska Curie grant agreement No. 705984. AN was supported by the MRC doctoral training program (MR/K501384/1).

\section{ACKNOWLEDGMENTS}

We thank the members of the Cantrell laboratory for comments on the manuscript, Alejandro Brenes for providing us with analytic tool support, the Flow Cytometry Facility (A. Whigham, M. Lee, V. Reid, A. Gardner and R. Clarke), the biological sciences research unit at the University of Dundee, the Proteomics Facility (D. Lamont and team, Dundee), the Finnish Functional Genomics Centre and the Medical Bioinformatics Centre of Turku Biosciences that is supported by University of Turku, Abo Akademi University, Biocenter Finland and Elixir-Finland.

\section{SUPPLEMENTARY MATERIAL}

The Supplementary Material for this article can be found online at: https://www.frontiersin.org/articles/10.3389/fimmu.2021. 691997/full\#supplementary-material

\section{REFERENCES}

1. Curtsinger JM, Mescher MF. Inflammatory Cytokines as a Third Signal for $\mathrm{T}$ Cell Activation. Curr Opin Immunol (2010) 22(3):333-40. doi: 10.1016/ j.coi.2010.02.013

2. Cantrell D. Signaling in Lymphocyte Activation. Cold Spring Harb Perspect Biol (2015) 7(6):a018788. doi: 10.1101/cshperspect.a018788

3. Costello PS, Gallagher M, Cantrell DA. Sustained and Dynamic Inositol Lipid Metabolism Inside and Outside the Immunological Synapse. Nat Immunol (2002) 3(11):1082-9. doi: 10.1038/ni848

4. Garcon F, Patton DT, Emery JL, Hirsch E, Rottapel R, Sasaki T, et al. CD28 Provides T-Cell Costimulation and Enhances PI3K Activity at the Immune Synapse Independently of Its Capacity to Interact With the p85/p110 Heterodimer. Blood (2008) 111(3):1464-71. doi: 10.1182/blood-2007-08-108050

5. Stark AK, Chandra A, Chakraborty K, Alam R, Carbonaro V, Clark J, et al. PI3Kdelta Hyper-Activation Promotes Development of B Cells That Exacerbate Streptococcus Pneumoniae Infection in an AntibodyIndependent Manner. Nat Commun (2018) 9(1):3174. doi: 10.1038/s41467018-05674-8

6. Ross SH, Rollings C, Anderson KE, Hawkins PT, Stephens LR, Cantrell DA. Phosphoproteomic Analyses of Interleukin 2 Signaling Reveal Integrated JAK Kinase-Dependent and -Independent Networks in CD8(+) T Cells. Immunity (2016) 45(3):685-700. doi: 10.1016/j.immuni.2016.07.022

7. Hukelmann JL, Anderson KE, Sinclair LV, Grzes KM, Murillo AB, Hawkins PT, et al. The Cytotoxic T Cell Proteome and Its Shaping by the Kinase mTOR. Nat Immunol (2016) 17(1):104-12. doi: 10.1038/ni.3314

8. So L, Fruman DA. PI3K Signalling in B- and T-Lymphocytes: New Developments and Therapeutic Advances. Biochem J (2012) 442(3):465-81. doi: 10.1042/BJ20112092

9. Okkenhaug K, Ali K, Vanhaesebroeck B. Antigen Receptor Signalling: A Distinctive Role for the p110delta Isoform of PI3K. Trends Immunol (2007) 28(2):80-7. doi: 10.1016/j.it.2006.12.007
Supplementary Data Sheet 1 | CD8 naive and TCR activated $24 \mathrm{~h} \pm$ inhibitor RNAseq data.

Supplementary Data Sheet 2 | Unstim and TCR stimulated $4 \mathrm{~h} \mathrm{CTL} \pm$ inhibitors RNAseq data.

Supplementary Data Sheet 3 | WT and FOXO1-GFP KO CTL \pm inhibitor $24 \mathrm{~h}$ RNAseq data.

Supplementary Data Sheet 4 | Unstim and TCR stimulated 4 h CTL \pm inhibitors proteomic data.

Supplementary Table 1 | mRNA changing significantly in naïve CD8+ T cells after $24 \mathrm{~h}$ TCR activation.

Supplementary Table 2 | mRNA changing significantly in $24 \mathrm{~h}$ TCR activated cells after PI3K p1108 inhibition.

Supplementary Table 3 | mRNA changing significantly in CTL after $4 \mathrm{~h}$ TCR retriggering.

Supplementary Table 4 | mRNA changing significantly in $4 \mathrm{~h}$ TCR retriggered CTL after PI3K p1108 inhibition.

Supplementary Table 5 | mRNA changing significantly in WT CTL after $24 \mathrm{~h}$ PI3K p1108 inhibition.

Supplementary Table 6 | mRNA changing significantly in PI3K p110 treated FOXO1-GFP KO versus WT treated CTL.

Supplementary Table 9 | mRNA changing significantly in $4 \mathrm{~h}$ TCR retriggered CTL after ERK1-2 inhibition.

10. Angulo I, Vadas O, Garcon F, Banham-Hall E, Plagnol V, Leahy TR, et al. Phosphoinositide 3-Kinase Delta Gene Mutation Predisposes to Respiratory Infection and Airway Damage. Science (2013) 342(6160):866-71. doi: 10.1126/ science. 1243292

11. Lucas CL, Kuehn HS, Zhao F, Niemela JE, Deenick EK, Palendira U, et al. Dominant-Activating Germline Mutations in the Gene Encoding the PI(3)K Catalytic Subunit p110delta Result in T Cell Senescence and Human Immunodeficiency. Nat Immunol (2014) 15(1):88-97. doi: 10.1038/ ni. 2771

12. Sogkas G, Fedchenko M, Dhingra A, Jablonka A, Schmidt RE, Atschekzei F. Primary Immunodeficiency Disorder Caused by Phosphoinositide 3-Kinase Delta Deficiency. J Allergy Clin Immunol (2018) 142(5):1650-3.e2. doi: 10.1016/j.jaci.2018.06.039

13. Swan DJ, Aschenbrenner D, Lamb CA, Chakraborty K, Clark J, Engelhardt $\mathrm{KR}$, et al. Immunodeficiency, Autoimmune Thrombocytopenia and Enterocolitis Caused by Autosomal Recessive Deficiency of PIK3CDEncoded Phosphoinositide 3-Kinase $\delta$. Haematologica (2019) 104:483-6. doi: 10.3324/haematol.2018.208397

14. Billottet C, Grandage VL, Gale RE, Quattropani A, Rommel C, Vanhaesebroeck B, et al. A Selective Inhibitor of the p110delta Isoform of PI 3-Kinase Inhibits AML Cell Proliferation and Survival and Increases the Cytotoxic Effects of VP16. Oncogene (2006) 25(50):6648-59. doi: 10.1038/ sj.onc. 1209670

15. Dienstmann R, Rodon J, Serra V, Tabernero J. Picking the Point of Inhibition: A Comparative Review of PI3K/AKT/mTOR Pathway Inhibitors. Mol Cancer Ther (2014) 13(5):1021-31. doi: 10.1158/1535-7163.MCT-13-0639

16. Yang J, Nie J, Ma X, Wei Y, Peng Y, Wei X. Targeting PI3K in Cancer: Mechanisms and Advances in Clinical Trials. Mol Cancer (2019) 18(1):26. doi: 10.1186/s12943-019-0954-x

17. Eschweiler S, Ramírez-Suástegui C, King E, Chudley L, Thomas J, Wood O, et al. Immunomodulatory Effects of PI3K $\delta$ Inhibition in Solid Tumors Evaluation in a Randomized Phase II Trial. doi: 1021203/rs3rs-337290/v1 
18. Kim EH, Sullivan JA, Plisch EH, Tejera MM, Jatzek A, Choi KY, et al. Signal Integration by AKT Regulates CD8 T Cell Effector and Memory Differentiation. J Immunol (2012) 188(9):4305-14. doi: 10.4049/jimmunol.1103568

19. Gubbels Bupp MR, Edwards B, Guo C, Wei D, Chen G, Wong B, et al. T Cells Require Foxol to Populate the Peripheral Lymphoid Organs. Eur J Immunol (2009) 39(11):2991-9. doi: 10.1002/eji.200939427

20. Kerdiles YM, Beisner DR, Tinoco R, Dejean AS, Castrillon DH, DePinho RA, et al. Foxo1 Links Homing and Survival of Naive T Cells by Regulating LSelectin, CCR7 and Interleukin 7 Receptor. Nat Immunol (2009) 10(2):17684. doi: $10.1038 /$ ni. 1689

21. Ouyang W, Beckett O, Flavell RA, Li MO. An Essential Role of the Forkheadbox Transcription Factor Foxo1 in Control of $\mathrm{T}$ Cell Homeostasis and Tolerance. Immunity (2009) 30(3):358-71. doi: 10.1016/j.immuni.2009.02.003

22. Rollings CM, Sinclair LV, Brady HJM, Cantrell DA, Ross SH. Interleukin-2 Shapes the Cytotoxic T Cell Proteome and Immune Environment-Sensing Programs. Sci Signaling (2018) 11(526):eaap8112. doi: 10.1126/scisignal.aap8112

23. Macintyre AN, Finlay D, Preston G, Sinclair LV, Waugh CM, Tamas P, et al. Protein Kinase B Controls Transcriptional Programs That Direct Cytotoxic T Cell Fate But Is Dispensable for T Cell Metabolism. Immunity (2011) 34 (2):224-36. doi: 10.1016/j.immuni.2011.01.012

24. Luo CT, Li MO. Foxo Transcription Factors in T Cell Biology and Tumor Immunity. Semin Cancer Biol (2018) 50:13-20. doi: 10.1016/j.semcancer.2018.04.006

25. Hedrick SM, Hess Michelini R, Doedens AL, Goldrath AW, Stone EL. FOXO Transcription Factors Throughout T Cell Biology. Nat Rev Immunol (2012) 12 (9):649-61. doi: 10.1038/nri3278

26. Utzschneider DT, Delpoux A, Wieland D, Huang X, Lai CY, Hofmann M, et al. Active Maintenance of T Cell Memory in Acute and Chronic Viral Infection Depends on Continuous Expression of FOXO1. Cell Rep (2018) 22 (13):3454-67. doi: 10.1016/j.celrep.2018.03.020

27. Delpoux A, Lai CY, Hedrick SM, Doedens AL. FOXO1 Opposition of CD8(+) T Cell Effector Programming Confers Early Memory Properties and Phenotypic Diversity. Proc Natl Acad Sci USA (2017) 114(42):E8865-E74. doi: 10.1073/pnas.1618916114

28. Staron MM, Gray SM, Marshall HD, Parish IA, Chen JH, Perry CJ, et al. The Transcription Factor FoxO1 Sustains Expression of the Inhibitory Receptor PD-1 and Survival of Antiviral CD8(+) T Cells During Chronic Infection. Immunity (2014) 41(5):802-14. doi: 10.1016/j.immuni.2014.10.013

29. Sinclair LV, Finlay D, Feijoo C, Cornish GH, Gray A, Ager A, et al. Phosphatidylinositol-3-OH Kinase and Nutrient-Sensing mTOR Pathways Control T Lymphocyte Trafficking. Nat Immunol (2008) 9(5):513-21. doi: 10.1038/ni.1603

30. Okkenhaug K, Bilancio A, Farjot G, Priddle H, Sancho S, Peskett E, et al. Impaired B and T Cell Antigen Receptor Signaling in P110 PI 3-Kinase Mutant Mice. Science (2002) 297:1031-4. doi: 10.1126/science.1073560

31. Pircher H, Biirki K, Lang R, Hengartner H, Zinkernagel RM. Tolerance Induction in Double Specific T-Cell Receptor Transgenic Mice Varies With Antigen. Nature (1989) 341:559-61. doi: 10.1038/342559a0

32. Stone EL, Pepper M, Katayama CD, Kerdiles YM, Lai CY, Emslie E, et al. ICOS Coreceptor Signaling Inactivates the Transcription Factor FOXO1 to Promote TFH Cell Differentiation. Immunity (2015) 42(2):239-51. doi: 10.1016/j.immuni.2015.01.017

33. Jacob J, Baltimore D. Modelling T-Cell Memory by Genetic Marking of Memory Tcells In Vivo. Nature (1999) 399:593-7. doi: 10.1038/21208

34. Dobin A, Davis CA, Schlesinger F, Drenkow J, Zaleski C, Jha S, et al. STAR: Ultrafast Universal RNA-Seq Aligner. Bioinformatics (2013) 29(1):15-21. doi: 10.1093/bioinformatics/bts635

35. Ewels P, Magnusson M, Lundin S, Kaller M. MultiQC: Summarize Analysis Results for Multiple Tools and Samples in a Single Report. Bioinformatics (2016) 32(19):3047-8. doi: 10.1093/bioinformatics/btw354

36. Robinson MD, McCarthy DJ, Smyth GK. edgeR: A Bioconductor Package for Differential Expression Analysis of Digital Gene Expression Data. Bioinformatics (2010) 26(1):139-40. doi: 10.1093/bioinformatics/btp616

37. McCarthy DJ, Chen Y, Smyth GK. Differential Expression Analysis of Multifactor RNA-Seq Experiments With Respect to Biological Variation. Nucleic Acids Res (2012) 40(10):4288-97. doi: 10.1093/nar/gks042

38. Lawrence M, Huber W, Pages H, Aboyoun P, Carlson M, Gentleman R, et al. Software for Computing and Annotating Genomic Ranges. PLoS Comput Biol (2013) 9(8):e1003118. doi: 10.1371/journal.pcbi.1003118
39. Ritchie ME, Phipson B, Wu D, Hu Y, Law CW, Shi W, et al. Limma Powers Differential Expression Analyses for RNA-sequencing and Microarray Studies. Nucleic Acids Res (2015) 43(7):e47. doi: 10.1093/nar/gkv007

40. Oliveros JC. Venny. An Interactive Tool for Comparing Lists With Venn Diagrams. (2007). Available at: https://bioinfogp.cnb.csic.es/tools/venny_old/venny.php

41. Marchingo JM, Sinclair LV, Howden AJ, Cantrell DA. Quantitative Analysis of How Myc Controls T Cell Proteomes and Metabolic Pathways During T Cell Activation. Elife (2020) 5:e53725. doi: 10.7554/eLife.53725

42. Wisniewski JR, Hein MY, Cox J, Mann M. A "Proteomic Ruler" for Protein Copy Number and Concentration Estimation Without Spike-in Standards. Mol Cell Proteomics (2014) 13(12):3497-506. doi: 10.1074/mcp.M113.037309

43. Finlay DK, Rosenzweig E, Sinclair LV, Feijoo-Carnero C, Hukelmann JL, Rolf J, et al. PDK1 Regulation of mTOR and Hypoxia-Inducible Factor 1 Integrate Metabolism and Migration of CD8+ T Cells. J Exp Med (2012) 209(13):244153. doi: 10.1084/jem.20112607

44. Wang R, Dillon CP, Shi LZ, Milasta S, Carter R, Finkelstein D, et al. The Transcription Factor Myc Controls Metabolic Reprogramming Upon T Lymphocyte Activation. Immunity (2011) 35(6):871-82. doi: 10.1016/ j.immuni.2011.09.021

45. Brewitz A, Eickhoff S, Dahling S, Quast T, Bedoui S, Kroczek RA, et al. CD8(+) T Cells Orchestrate pDC-XCR1(+) Dendritic Cell Spatial and Functional Cooperativity to Optimize Priming. Immunity (2017) 46(2):205-19. doi: 10.1016/j.immuni.2017.01.003

46. Castellino F, Huang AY, Altan-Bonnet G, Stoll S, Scheinecker C, Germain RN. Chemokines Enhance Immunity by Guiding Naive CD8+ T Cells to Sites of CD4+ T Cell-Dendritic Cell Interaction. Nature (2006) 440(7086):890-5. doi: 10.1038/nature04651

47. Luff DH, Wojdyla K, Oxley D, Chessa T, Hudson K, Hawkins PT, et al. PI3kdelta Forms Distinct Multiprotein Complexes at the TCR Signalosome in Naive and Differentiated CD4(+) T Cells. Front Immunol (2021) 12:631271. doi: 10.3389/fimmu.2021.631271

48. Howden AJM, Hukelmann JL, Brenes A, Spinelli L, Sinclair LV, Lamond AI, et al. Quantitative Analysis of T Cell Proteomes and Environmental Sensors During T Cell Differentiation. Nat Immunol (2019) 20(11):1542-54. doi: 10.1038/s41590-019-0495-x

49. Waugh C, Sinclair L, Finlay D, Bayascas JR, Cantrell D. Phosphoinositide $(3,4,5)-$ Triphosphate Binding to Phosphoinositide-Dependent Kinase 1 Regulates a Protein Kinase B/Akt Signaling Threshold That Dictates T-Cell Migration, Not Proliferation. Mol Cell Biol (2009) 29(21):5952-62. doi: 10.1128/MCB.00585-09

50. Delpoux A, Marcel N, Hess Michelini R, Katayama CD, Allison KA, Glass CK, et al. FOXO1 Constrains Activation and Regulates Senescence in CD8 T Cells. Cell Rep (2021) 34(4):108674. doi: 10.1016/j.celrep.2020.108674

51. Damasio MP, Marchingo JM, Spinelli L, Hukelmann JL, Cantrell DA, Howden AJM. Extracellular Signal-Regulated Kinase (ERK) Pathway Control of CD8+ T Cell Differentiation. Biochem J (2021) 478(1):79-98. doi: 10.1042/BCJ20200661

52. Eberlein J, Davenport B, Nguyen TT, Victorino F, Jhun K, van der Heide V, et al. Chemokine Signatures of Pathogen-Specific T Cells I: Effector T Cells. J Immunol (2020) 205(8):2169-87. doi: 10.4049/jimmunol.2000253

53. Chen S, Lee LF, Fisher TS, Jessen B, Elliott M, Evering W, et al. Combination of 4-1BB Agonist and PD-1 Antagonist Promotes Antitumor Effector/ Memory CD8 T Cells in a Poorly Immunogenic Tumor Model. Cancer Immunol Res (2015) 3(2):149-60. doi: 10.1158/2326-6066.CIR-14-0118

54. Zhou AC, Wagar LE, Wortzman ME, Watts TH. Intrinsic 4-1BB Signals Are Indispensable for the Establishment of an Influenza-Specific Tissue-Resident Memory CD8 T-Cell Population in the Lung. Mucosal Immunol (2017) 10 (5):1294-309. doi: 10.1038/mi.2016.124

55. Zhou AC, Batista NV, Watts TH. 4-1BB Regulates Effector CD8 T Cell Accumulation in the Lung Tissue Through a TRAF1-, mTOR-, and AntigenDependent Mechanism to Enhance Tissue-Resident Memory T Cell Formation During Respiratory Influenza Infection. J Immunol (2019) 202 (8):2482-92. doi: 10.4049/jimmunol.1800795

56. Wang N, Keszei M, Halibozek P, Yigit B, Engel P, Terhorst C. Slamf6 Negatively Regulates Autoimmunity. Clin Immunol (2016) 173:19-26. doi: 10.1016/j.clim.2016.06.009

57. Brunet JF, Denizot F, Luciani M-F, Roux-Dosseto M, Suzan M, Matteit MG, et al. A New Member of the Immunoglobulin Superfamily-CfLA-4. Nature (1987) 328:267-70. doi: 10.1038/328267a0 
58. Korman A, Yellin M TK. Tumor Immunotherapy: Preclinical and Clinical Activity of Anti-CTLA4 Antibodies. Curr Opin Investig Drugs (2005) 6:582-91.

59. Palazon A, Tyrakis PA, Macias D, Velica P, Rundqvist H, Fitzpatrick S, et al. An HIF-1alpha/VEGF-A Axis in Cytotoxic T Cells Regulates Tumor Progression. Cancer Cell (2017) 32(5):669-83.e5. doi: 10.1016/j.ccell.2017.10.003

60. Yigit B, Wang N, Ten Hacken E, Chen SS, Bhan AK, Suarez-Fueyo A, et al. SLAMF6 as a Regulator of Exhausted CD8(+) T Cells in Cancer. Cancer Immunol Res (2019) 7(9):1485-96. doi: 10.1158/2326-6066.CIR-18-0664

61. Sandu I, Cerletti D, Oetiker N, Borsa M, Wagen F, Spadafora I, et al. Landscape of Exhausted Virus-Specific CD8 T Cells in Chronic LCMV Infection. Cell Rep (2020) 32(8):108078. doi: 10.1016/j.celrep.2020.108078
Conflict of Interest: The authors declare that the research was conducted in the absence of any commercial or financial relationships that could be construed as a potential conflict of interest.

Copyright $\odot 2021$ Spinelli, Marchingo, Nomura, Damasio and Cantrell. This is an open-access article distributed under the terms of the Creative Commons Attribution License (CC BY). The use, distribution or reproduction in other forums is permitted, provided the original author(s) and the copyright owner(s) are credited and that the original publication in this journal is cited, in accordance with accepted academic practice. No use, distribution or reproduction is permitted which does not comply with these terms. 